\title{
Chapter 19 \\ Thermodynamic Modelling in the Frames of the TRIP-Matrix-Composite Development
}

\author{
Ivan Saenko and Olga Fabrichnaya
}

\begin{abstract}
The present chapter is focused on thermodynamic modelling as a part of a complex development of metal-ceramic composite materials. Within this chapter the main examples of successful application of thermodynamic calculation for a solving of technological problems are highlighted, basic theory and methods of thermodynamic investigations and modelling are described in details and the most important results are briefly given. The purpose of this chapter is to give a deep understanding of thermodynamic modelling from basic experiments to modern methods of simulation. There is a set of recommendations for performing thermodynamic assessment and creation of multicomponent thermodynamic databases.
\end{abstract}

\subsection{Introduction}

Knowledge of phase equilibria and the underlying thermodynamics play a crucial role in the understanding of development and application of materials. Thereby, phase diagrams represent a kind of roadmaps for materials development and provide important information for understanding of technological aspects of design and usage of materials. However, the most of the modern materials consist of more than two or three components, what makes the graphical representation of these systems challenging and complex. Moreover, there is only limited information for many multicomponent systems. Method of computational thermodynamics is very powerful tool for prediction and extrapolation helping to fill these gaps of the areas without experimental information [1].

In the frame of a development of an innovative composite material, thermodynamic simulation using the CALPHAD method (Calculation of Phase Diagrams) can be used in order to support an optimization of chemical composition of the alloy and to develop a production process.

I. Saenko $\cdot$ O. Fabrichnaya $(\bowtie)$

Institute of Materials Science, Technische Universität Bergakademie Freiberg, Gustav-Zeuner-Str.

5, 09599 Freiberg, Germany

e-mail: fabrich@ww.tu-freiberg.de 
The TRIP-Matrix-Composite is an example of innovative material, which is based on high-alloyed austenitic TRIP-steel and reinforcing ceramic particles of zirconia partially stabilized by $\mathrm{MgO}$ (Mg-PSZ). Thereby, thermodynamic calculations can provide information about the stable and metastable phase formation in the material as well as the accompanying energetic effects and basic information of the physicochemical parameters of the manufacturing processes.

Metal Matrix Composites containing highly alloyed TRIP-steel as metallic component and $\mathrm{MgO}$ partially stabilized $\mathrm{ZrO}_{2}$ as ceramic component are considered as promising new construction materials with high energy absorption. Under deformation metastable austenite transforms into martensite, which results in an increasing strength. It should be mentioned that $\mathrm{MgO}$ stabilized $\mathrm{ZrO}_{2}$ also shows stress-induced martensitic transformation from tetragonal into monoclinic phase [2]. The increased toughness of this ceramic phase is attributed to a stress-induced transformation. For a good performance of the composite material a strong adhesion between the metallic and the ceramic components is required in order to transmit stresses between the different phases. The infiltration and powder metallurgy/sintering processes selected in the Collaborative Research Center 799 (CRC799) to produce $\mathrm{Fe}-\mathrm{ZrO}_{2}$ based TRIP matrix composites may cause heterogeneous reactions in the matrix materials, in the ceramic particles and at the interfaces that can significantly influence on the mechanical properties of final composite materials. This information can be used to derive the structure development in the constituent materials and their compatibility and long-term stability. Therefore, the CALPHAD method was applied in the CRC 799 for many years as a valuable tool for materials design as knowledge of the phases that are present in a material and their compositions is essential for modelling the behavior and properties. It was widely applied for optimization of chemical composition of steel matrix with following annealing improving of its microstructure [3], for prediction and understanding of the local deformation mechanisms [4], for modelling of interfacial reaction between steel matrix and ceramic particles [5], as well as for understanding of phase transformations of the metastable austenite into martensite in the $\mathrm{Fe}-\mathrm{CrMnNi}-\mathrm{N}-\mathrm{C}$ model alloy [6]. Additionally, the CALPHAD method provided a basement for further modelling method concerning the development of the TRIP-Matrix-Composite i.e. thermo-mechanical modelling [7], simulation of electron beam welding [8] and phase field modelling.

This Chapter will consider a basement of computational thermodynamics, reveal experimental side of thermodynamic modelling and present the latest results concerning the TRIP-Matrix-Composite development.

\subsection{Experimental Techniques}

Since the CALPHAD approach is a phenomenological method, its parametric functions must be assessed using experimental data before any prediction and/or extrapolation can be made. In order to get a maximum of information, all types of experimental measurements that are related to thermodynamic properties must be considered 
and assessed. Collected experimental data are applied for adjusting of optimized parameters of the Gibbs energy functions.

Thereby, the reliability and accuracy of the experimental data have to be critically evaluated taking into account, which one of the various experimental techniques was used. Measured experimental data can be roughly classified into a few principal types: "thermodynamic data" and "phase-diagram data" [9]. The most of thermodynamic data can be directly applied to describe Gibbs energy functions of individual phases, while experimental data on the phase relations can be used for optimization of those functions for reproducing of phase diagrams of the system and thermodynamic data within their uncertainty. Since the phase diagram is representing equilibrium states of the system corresponding to minimum of its Gibbs energy being the sum of the properties of the individual phases multiplied to their mole amount respectively [10] at various conditions the phase relations are dependent on thermodynamic properties of the individual phases. Optimization of the Gibbs energy functions is a complex procedure, which will be described further (Sect. 19.3.2).

\subsubsection{Sample Preparation}

Development of the TRIP-Matrix-Composite requires a multicomponent thermodynamic description, which would include all alloying elements of the matrix, as well as components of ceramics such as $\mathrm{ZrO}_{2}$ and $\mathrm{MgO}$ as well as oxides appearing due to steel oxidation and impurities. Consequently, both type of materials had to be investigated, not only steel matrix but also components of ceramics. Therefore, two different techniques of specimen preparation were applied for investigations of steel and ceramic systems.

In the case of steel systems, two or three components alloys were prepared by arc-melting method in Ar-atmosphere. Chemically pure metals were used as raw materials. Precursors have been weighed in accordance to the nominal compositions using laboratory scale ABJ 120-4M (KERN \& Sohn GmbH). In order to achieve good homogeneity of the chemical composition in the bulks, the samples were turned-over and re-melted three times during acr-melting. The melting chamber was evacuated to $\sim 10^{-5}$ atm and refilled with argon three times. An ingot of Ti (ca. $3 \mathrm{~g}$ ) was placed in one of the molds and was melted before the melting of the samples in order to adsorb rests of oxygen and prevent possible oxidation. The weight losses due to vaporization should be generally less than 1 mass $\%$. Next, samples obtained by arc melting were encapsulated in quartz tubes with reduced Ar atmosphere. The pressure of Ar was chosen in order to reach $1 \mathrm{~atm}$. at the homogenization temperature. The encapsulated samples were heat treated for a long time afterwards they were quenched into ice-cold water.

For ceramic systems, the co-precipitation method was used for sample preparation. Chemically pure salts of desired metals have been used as the initial materials. In the first step, the salts were diluted and dissolved by distilled water in order to obtain 
more suitable consistence for the co-precipitation process (solutions around of $0.4-$ $1.2 \mathrm{~mol} / \mathrm{l}$ in dependence on precursors). The concentration of obtained initial solutions was determined by Inductively Coupled Plasma-Optical Emission Spectrometry (ICP-OES) spectrometry. Calculated volumes of initial solutions were mixed together in order to get $\sim 2 \mathrm{~g}$ of oxide powder of desired molar ratio. The obtained solution was dropped from a burette at a low speed (around $1 \mathrm{ml}$ per minute) into a beaker containing about $500 \mathrm{ml}$ of the aqueous solution of $\mathrm{NH}_{4} \mathrm{OH}$ with $\mathrm{pH}$ value above 9.0. In order to increase particles in the obtained suspension, it was heated up and held at $333 \mathrm{~K}$ for $1-2 \mathrm{~h}$ before filtration. In order to control the chemical composition, co-precipitated suspension and filtrates were analyzed by ICP-OES. Since the composition of the samples obtained by ICP deviated significantly from nominal composition, an evaporation process was applied instead of filtration. Then, the substance obtained after filtration/evaporation was dried at $353 \mathrm{~K}$ for 2-3 days. Finally, pyrolysis of the dried precipitate powder was performed at 1073-1273 K for $3 \mathrm{~h}$ in air. The obtained oxide powder was pressed into cylindrical pellets at $250 \mathrm{MPa}$ and sintered in air atmosphere in Pt-crucibles using NABERTHERM furnace in order to reach equilibrium state. Annealing duration was chosen depending on sintering temperature and on development of microstructures.

\subsubsection{Phase-Diagram Data}

The quantities measured in phase diagrams are either temperatures of phase boundaries at fixed composition and invariant equilibria determined by thermal analysis or phase compositions at fixed temperatures determined by sample equilibration. There are several experimental methods for measuring the phase-diagram data. They are described in details by Lukas et al. [9]. In the frames of current investigation, X-ray powder diffraction (XRD), scanning electron microscopy combined with an energy dispersive X-ray spectrometry (SEM/EDX) and differential thermal analysis (DTA) were applied in order to get essential information about phase relations, required for thermodynamic assessment of two and three component system. Experimental data for multicomponent systems are usually not used directly in an assessment, but, if the extrapolation from the lower-order systems gives wrong results, one may use these data for modification of parameters describing the lower-order systems or by introducing high-order parameters and new phases. Additionally, if phases are not stable in a binary system the parameters of metastable phases can be assessed from a higher order system.

\subsubsection{Structural Investigation}

After long time annealing, the important step is to determine the phase assemblage of heat-treated samples. The most powerful analytical techniques for identifying the phases is X-ray or neutron diffraction. Moreover, these techniques are also important 
for the determination of crystal structures. Lattice parameters and site occupancies as functions of composition and temperature can be obtained to provide detailed information about the internal lattice of crystalline substances, including cite occupancies, unit cell dimensions, bond-lengths and bond-angles. This information is necessary to find right models for thermodynamic description.

In the frames of current investigation, X-ray powder diffraction (XRD) was applied using URD63 diffractometer (Seifert, FPM, Freiberg, Germany) equipped with graphite monochromator and $\mathrm{CuK} \alpha$ radiation $(\lambda=1.5418 \AA)$. The goniometer of the diffractometer has the Bragg-Brentano geometry. Powder samples were measured placed on monocrystalline silicon substrate with (510) orientation. In this case, the orientation of the substrate does not show any peak on the XRD patter in the range of $15^{\circ}-110^{\circ}$ of $2 \theta$. The Rietveld refinement was applied for the characterization of all measured diffraction patterns in order to obtain the volume fractions of present phases as well as lattice parameters. This method allows determining the siteoccupancy parameters by analyzing the polycrystalline samples. Each solid phase has its own characteristic diffraction pattern, as a function of intensity in dependence on the diffraction angle $2 \theta$. The program Maud [11] was used for Rietveld refinement.

\subsubsection{Microstructural Investigation}

A very useful tool in phase-diagram determination is micrography at higher magnification using a scanning electron microscope (SEM), or a transmission electron microscope (TEM). Equipped with an energy dispersive spectrometer (EDS), these devices allow measuring the chemical composition of the microstructural features. For example, boundaries in phase diagrams, which are often deduced from results of characterization of sample series with different compositions after equilibration at fixed temperatures, can be plotted as composition versus a temperature. Afterword, these results can be applied for modelling of homogeneity ranges of solid phases etc.

The microstructures of the samples were analyzed using Scanning Electron Microscopy (SEM). The investigations were carried out on the LEO $1530 \mathrm{Gem}$ ini (Zeiss, Germany). The microscope was equipped with a field emission cathode, used at the acceleration voltage of $20 \mathrm{kV}$ with working distance of 8-10.5 mm. In addition, energy-dispersive X-ray spectroscopy (EDX) was used in order to verify chemical compositions of samples, to determine phase compositions which are also used for identification of phases, as well as to estimate composition of liquid in eutectic reactions. An uncertainty range for EDX measurement is around 2-4 at.\%.

For imaging in the SEM, samples must be electrically conductive, at least at their surface, and electrically grounded in order to prevent the accumulation of electrostatic charge at the surface at the interaction with the electron beam. Therefore, samples composed of oxides were grinded and polished and then coated with an ultrathin graphite layer. 


\subsubsection{Thermal Analysis}

Differential thermal analysis (DTA) was applied in order to detect temperatures of phase transitions and reactions occurring in the sample as well as melting temperatures. The technique of thermal analysis is based on the measuring of the temperature difference between the sample versus a reference as a function of time and temperature during programmed heating and cooling cycles. Any exothermic or endothermic changes occurring in the sample is registered by comparison with the reference as the temperature difference of the thermocouple signals in $\mu \mathrm{V}$ (thermal voltage). The inert material, which does not react with crucible and does not have phase transformations in the investigated temperature range can be used as a reference. However, it should be noted that empty crucibles are mostly used as reference at present.

In the frame of this work, DTA was performed using SETARAM SETSYS EVOLUTION 1750 (SE 1750) and SETARAM SETSYS EVOLUTION 2400 (SE 2400). The SE 1750 device equipped with a type B thermocouple ( $\mathrm{Pt} / \mathrm{Rh} 70 \% / 30 \%-\mathrm{Pt} / \mathrm{Rh}$ $94 \% / 6 \%$, by weight) works in an inert atmosphere of argon or helium in the interval of temperatures up to $2023 \mathrm{~K}$. The SE 2400 device equipped with a type C thermocouple (W/Re $95 \% / 5 \%$-W/Re $74 \% / 26 \%$, by weight) works in an inert atmosphere of helium up to $2673 \mathrm{~K}$. As the crucible's materials Pt/Rh10\% was used for SE 1750 and pure W was used for SE 2400 in the case of ceramic materials. For metallic samples, ceramic crucibles should be used. Thereby, corundum is the most common ceramic material.

Both if these devices have an opportunity for thermogravimetric analysis (TGA), which is very useful tool for measuring the mass change of a material as a function of temperature and time during heating and cooling program.

Calibration procedure of the apparatuses was systematically carried out by using pure reference elements with known melting temperatures. Measured temperatures were recounted according to a correction function acquired at the last correction procedure. Temperature calibration of SE 1750 was performed using melting points of $\mathrm{Al}, \mathrm{Ag}, \mathrm{Au}, \mathrm{Cu}$ and $\mathrm{Ni}$. The correction procedure for $\mathrm{SE} 2400$ was carried out using melting points of $\mathrm{Al}, \mathrm{Al}_{2} \mathrm{O}_{3}$ from literature and temperature of solid phase transformation in $\mathrm{LaYO}_{3}$ measured in SE 1750. These materials were chosen because of their passivity concerning to crucible's materials. Correction polynomials were obtained by fitting derived points using the least-squares method. The temperatures of transformations were determined as on-set point i.e. intersection of the tangent line constructed in the point of highest slope and baseline. Since correction procedures were carried out using on-set point, temperatures of transformations should be also determined by on-set points.

\subsubsection{Thermodynamic Data}

There are many different techniques for determining thermodynamic properties of individual phases directly. They are described in the book of Lukas et al. [9]. In 
this chapter, only two types of measurements will be discussed further, namely drop solution and differential scanning calorimetry that were used in the frames of current work.

\subsubsection{Differential Scanning Calorimetry}

In the present work, differential scanning calorimetry (DSC) measurements were carried out in order to obtain the heat capacity of single phases in the investigated systems. This information is important for the thermodynamic assessments and modelling of multicomponent systems. The heat capacity measurements in the temperature range from 235 to $675 \mathrm{~K}$ were carried out using the device DSC 8000 (Perkin Elmer, $\mathrm{Pt} / \mathrm{Rh}$ crucible, Ar or He flow, heating rate $10 \mathrm{~K} / \mathrm{min}$ ). The measurements in the temperature range from 235 to $675 \mathrm{~K}$ were divided into small intervals of $100-150 \mathrm{~K}$. The DSC measurements in the temperature range from 623 to $1220 \mathrm{~K}$ were performed in one temperature range using the device DSC Pegasus 404C (NETZSCH, Pt/Rh crucible, Ar flow, heating rate $10 \mathrm{~K} / \mathrm{min}$ ).

The classical three-step continuous method [12] with a constant heating rate was used to measure specific heat capacity:

- The determination of the heat flow rate of the zero-line (with empty sample and reference sides). This step takes into account the heat capacity of inner parts of the device.

- The calibration step - a sample of the material, whose heat capacity is precisely defined (synthetic sapphire), is measured in the sample crucible.

- Calorimetrical measurement of an unknown sample.

Calibration was performed using a certified sapphire standard in the case of ceramic materials. For metallic systems, calibration was performed using certified standard materials depending on the reliable temperature range of their heat capacity: copper standard was used in the temperature range from 100 to $320 \mathrm{~K}$; molybdenum from 300 to $673 \mathrm{~K}$ and platinum from 573 to $1473 \mathrm{~K}$. The mass and radius of sample pellets were kept the same as for standard materials. The measurements of two different samples were repeated two times with maximal uncertainty $3 \%$. It should be mentioned that the $C_{P}$ measurements at high temperatures using DSC equipment are becoming less reliable due to increase of heat radiation which decreased registered signal. This effect was considered during fitting of the experimental data. Fitting of the obtained results was performed using the Maier-Kelley equation. In order to exclude any phase transformation during the heat capacity measurement, XRD analyses of the obtained samples were performed before the heat capacity measurements and afterward. 


\subsubsection{Drop Solution Calorimetry}

The principle of this method is that two (or more) different well-defined samples are combined in the calorimeter and react to give a single sample, which again must be well defined. Well defined means that all the variables upon which the enthalpy depends must be known: each sample must be in internal equilibrium; its temperature and composition must be known. Drop solution calorimetry method was applied in order to determine the enthalpy of formation of oxide compounds. These measurements were performed using an Alexis 800 heat-flux micro calorimeter (SETARAM, France). The samples pressed into pellets ( $\varnothing 1 \mathrm{~mm}$, mass 3-9 mg) were dropped directly from room temperature into the calorimeter with a solvent at $T=$ $973 \mathrm{~K}$ and the enthalpy increments of dropping and solution of a set of 9 pellets were measured. The sodium molybdate $3 \mathrm{Na}_{2} \mathrm{O} \cdot 4 \mathrm{MoO}_{3}$ was used as the solvent. The calorimeter was calibrated by using the molar enthalpy increment of dropping standard sapphire spheres. Error of the measurement was stated to be twice the standard deviation of the mean value.

\subsection{CALPHAD Method}

Computational thermodynamics is powerful tool for solution of various problems in materials science, particularly used in the construction of phase diagrams [10]. At the beginning of the previous century, a thermodynamic modelling a phase diagrams of a metal-based system was firstly performed by Johannes van Laar using regular solutions models, what has evolved in more recent years to the CALPHAD (Calculation of Phase Diagrams) [13]. The CALPHAD method has been pioneered by American metallurgist Larry Kaufman since the 1970s [9, 14, 15]. Calculation of phase equilibrium is based on minimization of the Gibbs energy of the system which is the sum of the Gibbs energies of individual phases multiplied respectively to their mole amount or from equality of chemical potential for components in the equilibrated phases. The Gibbs energy of individual phase is described by thermodynamic model representing its dependence on temperature, pressure and composition [14]. Therefore, phase diagrams are related to the thermodynamic properties of individual phases which can be also determined experimentally using calorimetry, vapor pressure measurements and electrochemical data. These different kinds of data are used for optimization of thermodynamic parameters simultaneously to reproduce both phase diagrams and experimental thermodynamic data. The obtained set of thermodynamic descriptions of individual phases can be used to calculate different kinds of phase diagrams.

It should be noted that thermodynamic data of some components are very well determined and they are not optimized, the other parameters such as mixing parameters of solution phases and metastable end-members of solid solutions should be optimized. The thermodynamic properties of intermediate phases usually also need to be optimized. The aim of the CALPHAD method is to obtain a consistent description of all phases in the system reproducing the thermodynamic properties 
and phase diagrams within uncertainty of measurements. The self-consistent thermodynamic database allows predicting of the phase relations and thermodynamic properties in regions where experimental information is not available as well as calculation of metastable phase diagrams, calculation of diffusion-less transformation and simulations of non-equilibrium processes assuming local equilibration.

Methodology of the CALPHAD method and main principles of thermodynamic databases development are described in many fundamental books [9, 14-16] and basics research $[1,17]$. In this chapter, the main information about CALPHAD will be described very shortly.

\subsubsection{Methodology}

The Gibbs energy is described as a function of temperature, pressure and composition. The thermodynamic descriptions of this function of the pure phases of end members of solid solutions at a certain $P$ and $T$ referred to the enthalpy of its phase at room temperature $298 \mathrm{~K}$ are in the following form:

$$
G(P, T)=\Delta_{f} H_{298}^{0}+\int_{298}^{T} C_{P} \mathrm{~d} T-T\left(S_{298}^{0}+\int_{298}^{T}\left(C_{P} / T\right) \mathrm{d} T\right)+\int_{1}^{P} V \mathrm{~d} P
$$

where $S_{298}^{0}$ is the standard entropy, $\Delta_{f} H_{298}^{0}$ is the enthalpy of formation and $C_{P}$ is the heat capacity given by

$$
C_{P}=a+b T+c T^{-2}+d T^{2}+e T^{-3}+\cdots
$$

The magnetic contribution $\mathrm{G}_{\mathrm{mag}}$ can be taken into account according to IndenHillert-Jarl [18] formalism (19.3).

$$
\mathrm{G}_{\mathrm{mag}}=T R \ln \left(\beta_{0}+1\right) g(\tau)
$$

where $\tau=T / T^{*}, T^{*}$ is the critical temperature (the Curie temperature $T_{\mathrm{C}}$ for ferromagnetic materials or the Neel temperature $T_{\mathrm{N}}$ for antiferromagnetic materials), $\beta_{0}$ the average magnetic moment per atom and $g(\tau)$ is a function depending on $\tau$ [19].

The molar volume in (19.1) is calculated as a function of pressure and temperature using the Murnaghan equation,

$$
V(P, T)=V(1, T)\left(1+\frac{K_{P}^{\prime} \cdot P}{K_{T}}\right)^{-1 / K^{\prime} P}
$$

where $K_{T}$ is isothermal bulk modulus, which can be expressed as 


$$
K_{T}=1 /\left(\beta_{0}+\beta_{1} T+\beta_{2} T^{2}+\beta_{3} T^{3}\right)
$$

and $K^{\prime}{ }_{P}$ is the pressure derivative of bulk modulus which in some cases has a temperature dependency:

$$
K_{P}^{\prime}=K_{P 298}^{\prime}+K_{P T}^{\prime}(T-298) \ln \left(\frac{T}{298}\right)
$$

$K_{P 298}^{\prime}$ is the pressure derivative of bulk modulus at $298 \mathrm{~K}, K_{P T}^{\prime}$ is its temperature derivative.

The molar volume at 1 bar is expressed as a function of temperature

$$
V(1, T)=V_{1,298}^{0} \exp \left(\int_{298}^{T} \alpha(T) \mathrm{d} T\right)
$$

where $V_{1,298}^{0}$ is the molar volume at 1 bar and $289 \mathrm{~K} . \alpha(T)$ is the temperature dependent thermal expansion

$$
\alpha(T)=\alpha_{0}+\alpha_{1} T+\alpha_{2} T^{-1}+\alpha_{3} T^{-2}
$$

The Gibbs energy $G_{A_{a} B_{b}}(T)$ of a stoichiometric phase $A_{a} B_{b}$ in case of absence of heat capacity data was modeled using Neumann-Kopp rule as:

$$
G_{A_{a} B_{b}}=a \mathrm{GHSER}_{A}+b \mathrm{GHSER}_{B}+\alpha+\beta T
$$

where $\mathrm{GHSER}_{i}$ is the Gibbs energy of the pure element $i$ referred to the enthalpy of pure element $i$ at $298 \mathrm{~K}$ in its standard element reference (SER) state, $\alpha$ and $\beta$ are parameters to be optimized.

Solution phases and stoichiometric phases with homogeneity ranges can be described by compound energy formalism [16].

The simplest non-ideal solution model is the substitutional model with the Gibbs energy of expressed as follows:

$$
G=\sum_{i}^{n} x_{i} G_{i}+R T \sum_{i}^{n} x_{i} \ln x_{i}+\Delta G^{\mathrm{Ex}}
$$

where $x_{i}$ are the mole fractions, $G_{i}$ is the Gibbs energy of an end-member $i, \sum_{i}^{n} x_{i} G_{i}$ is the surface of reference terms, $R T \sum_{i}^{n} x_{i} \ln x_{i}$ is the contribution to the Gibbs energy resulting from the configurational entropy of mixing for disordered solution, and $\Delta G^{\mathrm{Ex}}$ is the excess Gibbs energy of mixing.

The excess Gibbs energy of mixing was modelled using Redlich-Kister polynomials [20], expressed as: 


$$
\Delta G^{\mathrm{Ex}}=\sum_{i \neq j, i<j} x_{i} x_{j} \sum_{v=0}^{n} L_{i, j}^{v}\left(x_{i}-x_{j}\right)^{v}
$$

where $L_{i, j}^{v}$ is the mixing parameter between end-members $i$ and $j$, while $v$ is integer number.

The sublattice model in the form of compound energy formalism is used for solid phases having several crystallographic sites. The Gibbs energy of solution described by the sublattice model with three sublattices is given by

$$
\Delta G^{\mathrm{mix}}=\sum_{i} \sum_{j} \sum_{k} Y_{i}^{s} Y_{j}^{t} Y_{k}^{u} G_{i j k}+R T \sum_{s} \alpha_{s} \sum_{i} Y_{i}^{s} \ln \left(Y_{i}^{s}\right)+\Delta G^{\mathrm{Ex}}
$$

where $Y_{i}^{s}$ is the mole fraction of constituent $i$ on sublattice $s, \alpha_{s}$ is the number of sites on sublattice $s$ per mole of formula unit of phase and $\Delta G^{\mathrm{Ex}}$ is the excess Gibbs energy of mixing expressed as

$$
\begin{gathered}
\Delta G^{E}=\sum_{t} y_{j}^{t} \sum_{u} y_{k}^{u} \sum_{s} y_{i}^{s} y_{l}^{s} L_{i, l}^{s}+\sum_{s} y_{i}^{s} \sum_{t} y_{j}^{t} \sum_{u} y_{k}^{u} y_{m}^{u} L_{k, m}^{u} \\
+\sum_{s} y_{i}^{s} \sum_{u} y_{k}^{u} \sum_{t} y_{j}^{t} y_{n}^{t} L_{j, n}^{t} \\
L_{i, l}^{s}=\sum_{n}\left(Y_{i}^{s}-Y_{l}^{s}\right)^{n} L_{i, l}
\end{gathered}
$$

where $L_{i, l}^{s}$ are binary interaction parameters between species $i$ and $l$ on sublattice $s$. Higher-order interaction parameters could also be included giving more complicated excess Gibbs energy terms.

\subsubsection{Optimization}

The optimization process is the most important step of a creation of a thermodynamic database, which gives the best fit of experimental data taking into account the error of every data point. Each individual phase is described by thermodynamic model presenting an analytical function of the Gibbs energy dependence on temperature and composition (pressure is usually fixed at 1 bar) with adjustable parameters. These parameters are optimized using the least-squares method to obtain a description which reproduces experimental data with minimal deviation. However, the leastsquares method can work well only if the scatter of experimental data is completely random. Non-randomly distributed deviations of some data may completely destroy the utility of the least-squares method. They must be classified as systematic errors and excluded from the optimization. Therefore subjective judgments are required and decisions have to be taken on the selection of data during the optimization. From 
that point of view, the technique can also be called an assessment [9]. Unfortunately, including all available data in optimization does not necessarily lead to satisfactory results. Some experimental data could be in conflict to each other or can show large systematic errors. Thereby, setting different weights for these data points can help to recognize the influence of different experiments on the result of optimization. This procedure helps to identify which data are contradictory. However, it is usually impossible to optimize all parameters simultaneously. There are too many parameters and they have different influence on phase diagrams [17].

The optimization methodology of CALPHAD method can be subdivided into following stages:

1. Collection of diverse experimental information available in literature (crystallographic data for phases, phase equilibria, calorimetry, electrochemical data, vapor pressure measurements).

2. The selection of thermodynamic models based on crystallographic information for phases in the system under investigation. This implies selection of sublattices and their occupancies by constituents in agreement with crystal structure.

3. The consideration of temperature dependence of end-member parameters and introducing of mixing parameters for the Gibbs energy description of phase.

4. The optimization of the thermodynamic parameters using all available experimental as well as theoretical data.

5. The storage of the optimized parameters in computer-readable thermodynamic datasets.

6. The calculation of phase diagrams and various phase equilibria using the thermodynamic datasets.

The principle of the CALPHAD approach is schematically presented in Fig. 19.1.

\subsection{The Latest Results Concerning the TRIP-Matrix-Composite Development}

In the beginning of the development of the new composite, an extensive thermodynamic database for steel-based materials (Fe, Mn, Cr, Ni, Ti, Mo, W, V, Si, C and $\mathrm{N})$ was created in the frames of CALPHAD method. Therefore the main research point was focused on an optimization of the alloy for the matrix. Afterwards, focus of thermodynamic modelling was shifted to the development of a database for the ceramic materials $\left(\mathrm{ZrO}_{2}, \mathrm{MgO}, \mathrm{Al}_{2} \mathrm{O}_{3}, \mathrm{FeO}, \mathrm{Fe}_{2} \mathrm{O}_{3}, \mathrm{MnO}, \mathrm{Mn}_{2} \mathrm{O}_{3}\right)$.

In the beginning of the project, there were currently several thermodynamic databases for Fe-based multicomponent systems that were developed for the modelling of specific processes in the respective steels. They were based on critical assessments of binary and ternary systems available in the literature. For example, the TCFE7 commercial database included 25 elements and many binary and ternary systems (http://www.thermocalc.com/Products/Database). Moreover, this database contains descriptions of some solid oxide phases such as spinel, wustite and corundum in order to predict the tendency of different steels to oxidize. Additionally, there was the 


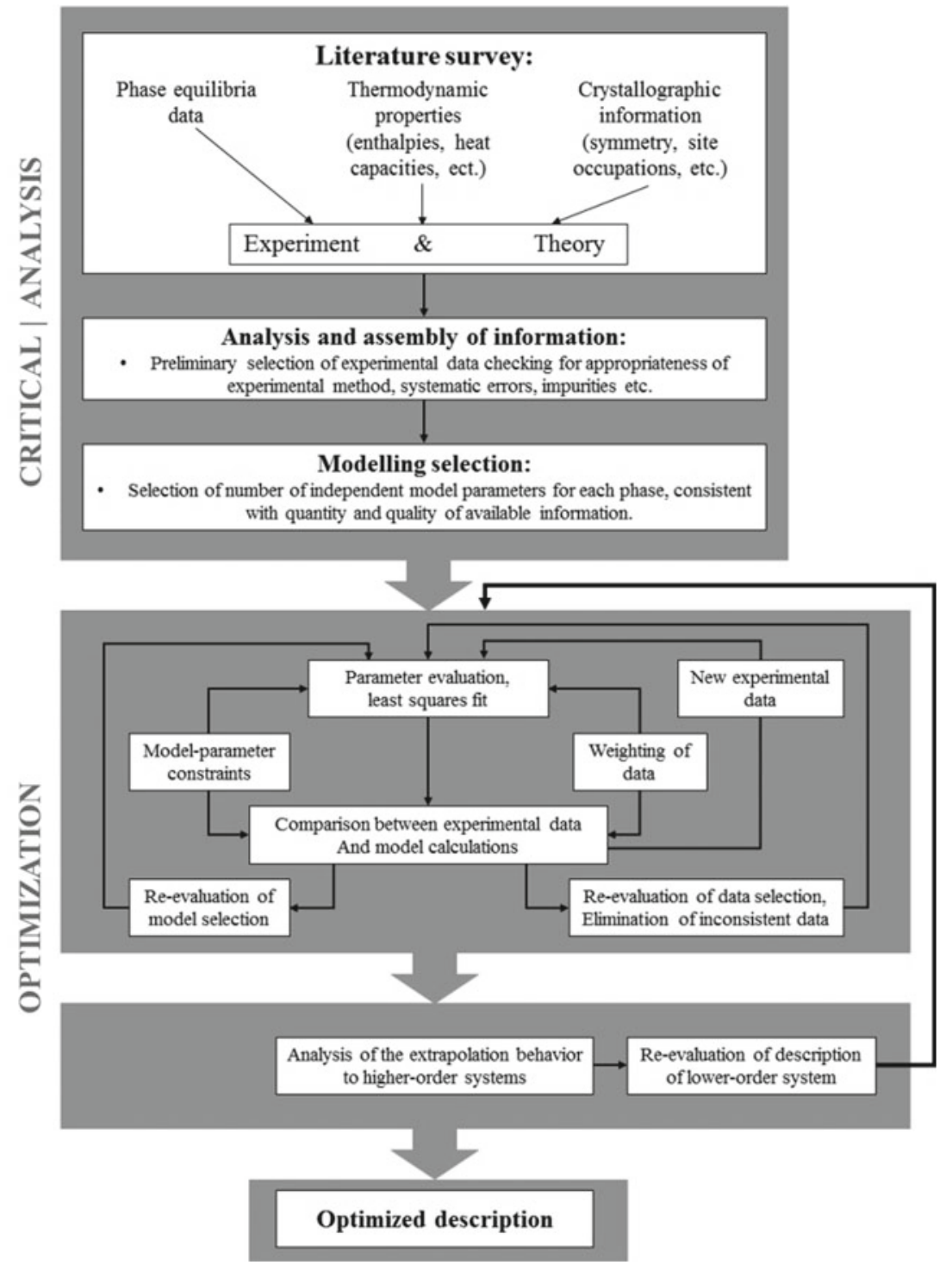

Fig. 19.1 A schematic diagram of the CALPHAD assessment

commercially available database TCOX, which contained 12 elements and descriptions of many oxide phases as well as the ionic melt, which describes both metallic and oxide melting behavior (http://www.thermocalc.com/Products/Database). However, all commercial databases have reproduced most of important binary system such as $\mathrm{Fe}-\mathrm{Mn}, \mathrm{Fe}-\mathrm{Ni}, \mathrm{Zr}-\mathrm{Mn}, \mathrm{Zr}-\mathrm{Fe}$ very poorly, what could not be accepted for deep process of materials design. 
A non-commercial steel database, which was under development in group of B. Hallstedt, contained 8 elements $\mathrm{Fe}, \mathrm{Al}, \mathrm{Mn}, \mathrm{Nb}, \mathrm{Si}, \mathrm{V}, \mathrm{C}$ and $\mathrm{N}$ and was aimed for modelling phase equilibria in Mn-rich steels [21]. However, this database did not include $\mathrm{Cr}$ and $\mathrm{Ni}$, which were very important for highly alloyed TRIP-steels. Therefore, the CRC 799 project required to develop a unique multicomponent steel database, which would fit all specific needs of design process in the fames of the TRIP-Matrix-Composite development.

A new thermodynamic database for steels containing eleven elements ( $\mathrm{Fe}, \mathrm{Mn}$, Mo, Cr, Ni, Ti, Si, V, W, N, C), has been developed by P. Franke within the first period of the CRC project [22]. Thermodynamic description of one of the most important systems $\mathrm{Fe}-\mathrm{Cr}-\mathrm{Ni}$ was developed based on advanced thermodynamic modelling. Obtained thermodynamic description considered magnetic contribution and chemical ordering in the $\mathrm{Fe}-\mathrm{Cr}-\mathrm{Ni}$ system [22]. This thermodynamic dataset for the ternary system $\mathrm{Cr}-\mathrm{Fe}-\mathrm{Ni}$ which has been reported in the literature for the range from medium to high temperatures has been supplemented with datasets from the binary subsystems at lower temperatures. The magnetic and the chemical ordering transitions which are known from the binary $\mathrm{Fe}-\mathrm{Ni}$ system were extrapolated into the ternary system $\mathrm{Cr}-\mathrm{Fe}-\mathrm{Ni}$. The phase diagram of $\mathrm{Cr}-\mathrm{Fe}-\mathrm{Ni}$ alloys at temperatures below $773 \mathrm{~K}$ was predicted (Fig. 19.2). The magnetic contribution to the Gibbs energy of Ni-rich alloys induces a miscibility gap which appears in the binary phase diagram of $\mathrm{Fe}-$ $\mathrm{Ni}$ as a small triangle-like field ending in a tricritical point. In the ternary system, $\mathrm{Cr}-\mathrm{Fe}-\mathrm{Ni}$ the miscibility gap is present as a broad two-phase field in the vicinity of the composition $\mathrm{FeNi}_{3}$. At lower temperatures, this miscibility gap participates in a sequence of changing equilibria when it interferes with the chemically ordered $\mathrm{L}_{12}$ phase.

Several ternary systems in the $\mathrm{Fe}-\mathrm{Mn}-\mathrm{Cr}-\mathrm{Ni}-\mathrm{Ti}-\mathrm{Si}-\mathrm{C}-\mathrm{N}$ system were accepted from literature data, checked for the consistency and published in LB series [23].
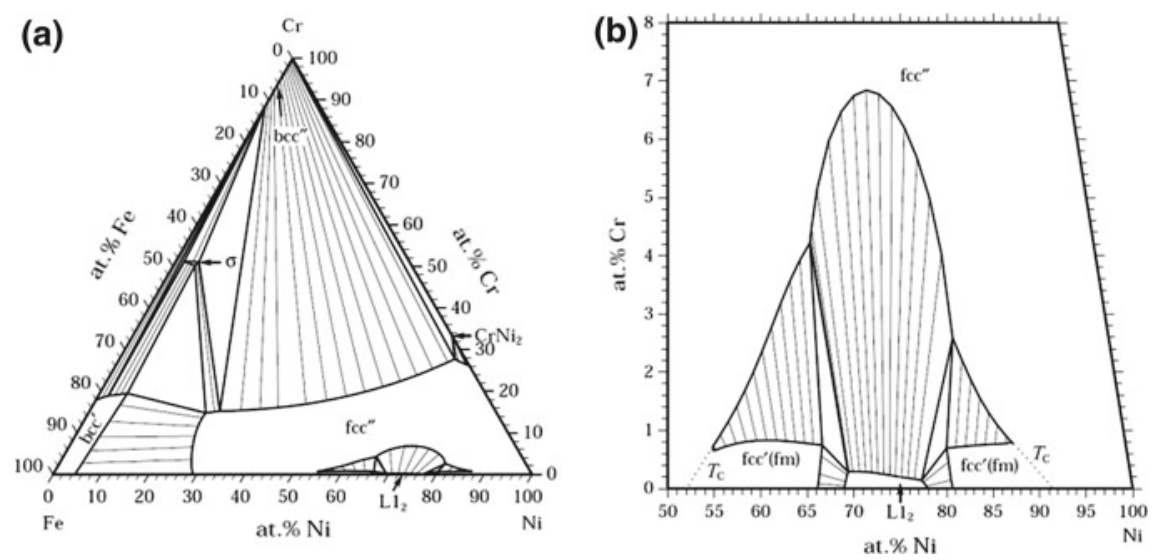

Fig. 19.2 a Calculated isothermal section of the $\mathrm{Fe}-\mathrm{Cr}-\mathrm{Ni}$ system at $773 \mathrm{~K}$; b Enlarged part of calculated isothermal section at $773 \mathrm{~K}$ [22] 
With this element selection calculations of the phase equilibria and modelling of the crystallization process using Scheil simulation for austenitic TRIP-steels became possible and reliable. Among the systems published in $\mathrm{LB}$ were $\mathrm{Fe}-\mathrm{Cr}-\mathrm{Mn}, \mathrm{Fe}-\mathrm{Cr}-$ $\mathrm{Ni}, \mathrm{Fe}-\mathrm{Cr}-\mathrm{C}, \mathrm{Fe}-\mathrm{Mn}-\mathrm{C}, \mathrm{Fe}-\mathrm{Ni}-\mathrm{C}$ and others. The developed database covers a wide range of evaluated systems in comparison with other available databases. Thus, it also covers non-iron systems.

The second milestone was the interfacial interaction between Mg-PSZ and steel, which was experimentally studied by Franke et al. [5]. Experimental details (SPS pre-sintering, annealing in Ar etc.) were reported in [5]. SEM/EDX investigations demonstrated the formation of $\mathrm{Mg}_{2} \mathrm{SiO}_{4}$ at the interface between the ceramic component and steel. It was determined that $\mathrm{Mg}$-PSZ contained $\mathrm{SiO}_{2}$ impurities around of 2.4 mass\%. It was stated, that another possible source for the $\mathrm{SiO}_{2}$ could be the $\mathrm{Si}$ content within the TRIP-steel ( $\sim .5$ mass $\%)$. Thermodynamic calculations were performed to explain destabilization of $\mathrm{Mg}$-PSZ and formation of $\mathrm{Mg}_{2} \mathrm{SiO}_{4}$ forsterite. The activity of $\mathrm{MgO}$ at the investigated temperature and the composition was calculated using the $\mathrm{ZrO}_{2}-\mathrm{MgO}$ thermodynamic database available in literature [24]. The $\mathrm{SiO}_{2}$ activity necessary for formations of silicates $\mathrm{Mg}_{2} \mathrm{SiO}_{4}$ and $\mathrm{MgSiO}_{3}$ was calculated using the thermodynamic data from literature [25]. Experimental studies of an interaction between steel and pure $\mathrm{ZrO}_{2}$ and between steel and $\mathrm{CaO}$ stabilized $\mathrm{ZrO}_{2}$ showed that silicates did not form at the investigated conditions [5]. Thermodynamic calculations were also performed for the $\mathrm{ZrO}_{2}-\mathrm{SiO}_{2}$ and $\mathrm{ZrO}_{2}-\mathrm{CaO}$ systems and ranges of the $\mathrm{SiO}_{2}$ activity were determined at which silicates should form. The oxygen partial pressure was calculated at which the $\mathrm{SiO}_{2}$ starts to form from Si dissolved in the steel. The corresponding limiting activity of Si in the TRIP-steel and the concentration of $\mathrm{Si}$ in the steel were calculated.

The ceramic material used in the present project is $\mathrm{ZrO}_{2}$ stabilized by 3.4 mass $\%$ of $\mathrm{MgO}$. A comprehensive thermodynamic assessment of the $\mathrm{ZrO}_{2}-\mathrm{MgO}$ system was available in literature. However, all of the data were based on a substitutional model for the solid and liquid phases. Consequently, re-assessment based on the more advanced modelling using the compound energy formalism had to be performed. Additionally, it was experimentally found that an addition of Titanium can improve bonding between $\mathrm{ZrO}_{2}$ ceramic particles and austenitic steel containing $\mathrm{Mn}, \mathrm{Cr}$ and $\mathrm{Ni}$ [26]. Therefore, ceramic systems containing $\mathrm{TiO}_{2}$ became one of the important tasks as well. Moreover, during the investigation of the interfacial interaction between $\mathrm{Mg}-\mathrm{PSZ}$ and steel [5] it was found that the $\mathrm{C}-\mathrm{ZrO}_{2}$ (fluorite) was destabilized due to reaction between $\mathrm{MgO}$ and impurities in ceramic material such as $\mathrm{Al}_{2} \mathrm{O}_{3}$ and $\mathrm{SiO}_{2}$. Therefore, systems with $\mathrm{Al}_{2} \mathrm{O}_{3}$ and $\mathrm{SiO}_{2}$ became one of the main points.

Thermodynamic descriptions of the systems $\mathrm{MgO}-\mathrm{Al}_{2} \mathrm{O}_{3}$ and $\mathrm{MnO}-\mathrm{Al}_{2} \mathrm{O}_{3}$ based on the compound energy formalism for solid phases and partially ionic liquid model were available in literature $[27,28]$. However, the model of the spinel phase in the $\mathrm{MnO}-\mathrm{Al}_{2} \mathrm{O}_{3}$ system had to be extended by introducing an interstitial sublattice to be compatible with the model used for the $\mathrm{MgO}-\mathrm{Al}_{2} \mathrm{O}_{3}$ system.

Many thermodynamic assessments for the systems containing $\mathrm{TiO}_{2}, \mathrm{Ti}_{2} \mathrm{O}_{3}, \mathrm{MgO}$, $\mathrm{FeO}, \mathrm{MnO}$ and other oxides were performed in the group of A. D. Pelton (http://www. sgte.org/fact/documentation/FToxide). Solid phases were modelled by the compound 
energy formalism, while the liquid phase was described by a modified quasi-chemical model [29]. The database for $\mathrm{ZrO}_{2}$-based systems was set up with the help of very limited experimental literature data. However, the $\mathrm{ZrO}_{2}$ containing phases do not contain the chemical element $\mathrm{Ti}$, which makes it impossible to calculate the interaction with titanium oxides, which are very important for the planned work. Commercial steel and oxide databases have been developed by the FactSage group (http://www. sgte.org/factsage/fact/factsage/FactSage). Although these databases contain descriptions for the $\mathrm{TiO}_{2}-\mathrm{Ti}_{2} \mathrm{O}_{3}-\mathrm{MO}$ systems $(\mathrm{M}=\mathrm{Mg}, \mathrm{Fe}, \mathrm{Mn})$, only very limited data are available for $\mathrm{ZrO}_{2}$-based systems. Model for liquid is not compatible with models used in the present study.

Therefore, the thermodynamic database of the $\mathrm{ZrO}_{2}-\mathrm{MgO}-\mathrm{MnO}-\mathrm{Al}_{2} \mathrm{O}_{3}$ system had to be developed for modelling of the interactions between $\mathrm{Al}_{2} \mathrm{O}_{3}$ impurities, Mg-PSZ and Fe-CrMnNi-TRIP-steels. In a similar way the $\mathrm{SiO}_{2}$ containing binary descriptions of the $\mathrm{MgO}-\mathrm{SiO}_{2}, \mathrm{MnO}-\mathrm{SiO}_{2}, \mathrm{ZrO}_{2}-\mathrm{SiO}_{2}$ systems had to be combined with databases of the $\mathrm{ZrO}_{2}-\mathrm{MgO}, \mathrm{ZrO}_{2}-\mathrm{MnO}$ systems and the thermodynamic database of the $\mathrm{ZrO}_{2}-\mathrm{MgO}-\mathrm{MnO}-\mathrm{SiO}_{2}$ system had to be developed to model phase relations between $\mathrm{SiO}_{2}$ impurities, $\mathrm{Mg}$-PSZ and the steel phases.

The thermodynamic description for the quasibinary system $\mathrm{ZrO}_{2}-\mathrm{MgO}$ (Fig. 19.3) was based on own experimental investigations with XRD, SEM/EDX and DTA as well as existing literature data [30]. The industrial Mg-PSZ ceramic was also tested in the initial state and after heat treatments at $1523 \mathrm{~K}$ with DTA. Differences between

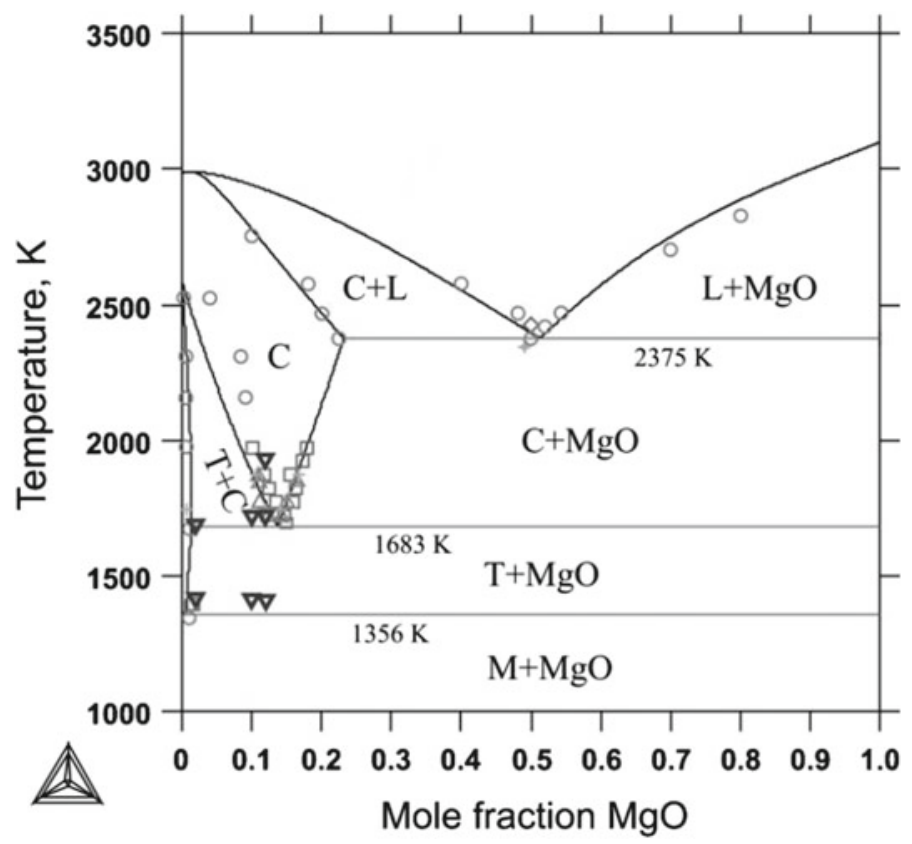

Fig. 19.3 The calculated $\mathrm{ZrO}_{2}-\mathrm{MgO}$ phase diagram together with experimental data [30] 
the calculations in the $\mathrm{ZrO}_{2}-\mathrm{MgO}$ and the experimental data could be attributed to the presence of $\mathrm{Al}_{2} \mathrm{O}_{3}$ additives in the industrially produced samples. The additives cause the formation of the $\mathrm{MgAl}_{2} \mathrm{O}_{4}$ phase with spinel structure.

As the $\mathrm{ZrO}_{2}-\mathrm{MgO}-\mathrm{Al}_{2} \mathrm{O}_{3}$ quasi-ternary system had only a very limited amount of experimental data available in literature, the phase equilibria were investigated in more detail in the work of Pavlyuchkov et al. [31]. Throughout the composition range, the solid phase equilibria in the $\mathrm{ZrO}_{2}-\mathrm{MgO}-\mathrm{Al}_{2} \mathrm{O}_{3}$ system were investigated using DTA, XRD, and SEM/EDX. Thereby, the isothermal sections at 1523, 1873 and 2023 K have been constructed. Furthermore, the stability of ternary X-phase at $2073 \mathrm{~K}$ found by Tassot et al. [32] was confirmed. The temperature limits of the X-phase stability limits were determined in the range between 1894 and $2094 \mathrm{~K}$. In addition, two ternary eutectic reactions and one eutectic maximum could be determined experimentally. The experimental data thus obtained were used to develop a thermodynamic description for this system. Thus, the liquidus and solidus surface projections and the isopleth section $\mathrm{ZrO}_{2}-\mathrm{MgAl}_{2} \mathrm{O}_{4}$ were calculated [31]. The calculations showed that much more complicated phase relations exist in this system in comparison to the literature data $[33,34]$. The calculated liquidus and solidus surface's projections of the $\mathrm{ZrO}_{2}-\mathrm{MgO}-\mathrm{Al}_{2} \mathrm{O}_{3}$ phase diagram are presented in Fig. 19.4.

As part of a separate work of Fabrichnaya and Pavlyuchkov [35], a thermodynamic description for the ternary $\mathrm{Zr}-\mathrm{Fe}-\mathrm{O}$ system using the $\mathrm{CalPhaD}$ approach was developed based on experimental data from literature. Thermodynamic parameters of $\mathrm{ZrO}_{2}-\mathrm{FeO}$ and $\mathrm{ZrO}_{2}-\mathrm{Fe}_{3} \mathrm{O}_{4}$ systems were assessed using literature data [36-38]. The solubility of $\mathrm{FeO}$ and $\mathrm{Fe}_{2} \mathrm{O}_{3}$ in the $\mathrm{ZrO}_{2}$ and of $\mathrm{ZrO}_{2}$ in the $\mathrm{Fe}_{2} \mathrm{O}_{3}$ and $\mathrm{Fe}_{3} \mathrm{O}_{4}$ phases were taken into account and described with the compound-energy formalism. The two sublattice model of partially ionic liquid was used for the description of the melt phase. The descriptions obtained for the $\mathrm{ZrO}_{2}-\mathrm{FeO}$ and $\mathrm{ZrO}_{2}-\mathrm{Fe}_{3} \mathrm{O}_{4}$ systems were combined into the description of the $\mathrm{ZrO}_{2}-\mathrm{FeO}-\mathrm{Fe}_{2} \mathrm{O}_{3}$ system. The isothermal section at $1473 \mathrm{~K}$ and the liquidus surface projection have been calculated for
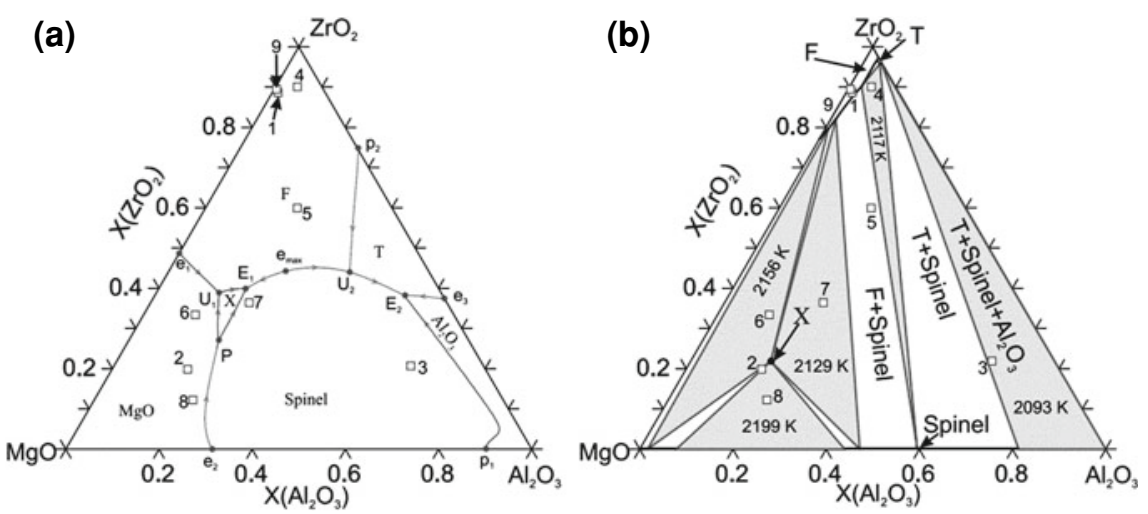

Fig. 19.4 Liquidus a and solidus $\mathbf{b}$ surface's projections of the $\mathrm{ZrO}_{2}-\mathrm{MgO}-\mathrm{Al}_{2} \mathrm{O}_{3}$ phase diagram [31] 
the system using the complex data set. The calculated isopleth sections $\mathrm{ZrO}_{2}-\mathrm{FeO}$ and $\mathrm{ZrO}_{2}-\mathrm{Fe}_{3} \mathrm{O}_{4}$ are shown in Fig. 19.5a, b together with the experimental data. Figure 19.6 shows the liquidus surface projection of the $\mathrm{ZrO}_{2}-\mathrm{FeO}-\mathrm{Fe}_{2} \mathrm{O}_{3}$ system. The equilibria between the metallic melt and the solid $\mathrm{ZrO}_{2}$ phase were calculated and compared with the literature values [39, 40]. Similar to other calculations [41], significant differences between the calculated oxygen solubilities in the $\mathrm{Fe}-\mathrm{Zr}$ melt and the experimental results were found. New experimental study should be performed to resolve this contradiction.

The phase equilibria in the systems $\mathrm{ZrO}_{2}-\mathrm{MnO}$ and $\mathrm{ZrO}_{2}-\mathrm{MnO}-\mathrm{Mn}_{2} \mathrm{O}_{3}$ were investigated experimentally with DTA in Ar atmosphere and by heat treatment in air in the temperature range between 1523 and $1873 \mathrm{~K}$ [42]. The reaction temperatures were determined with DTA-TG, the phase compositions in the samples with XRD and

(a)

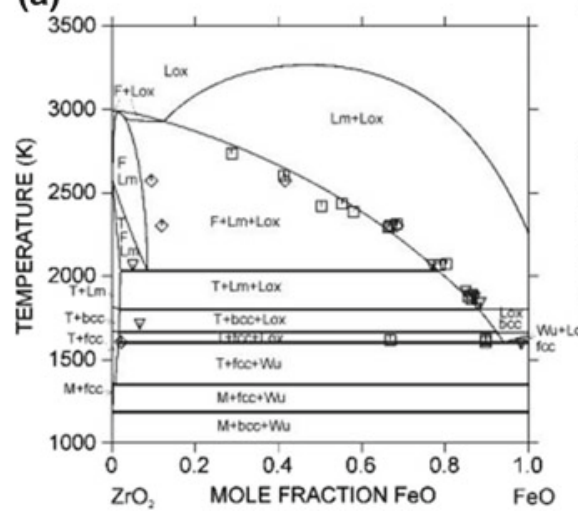

(b)

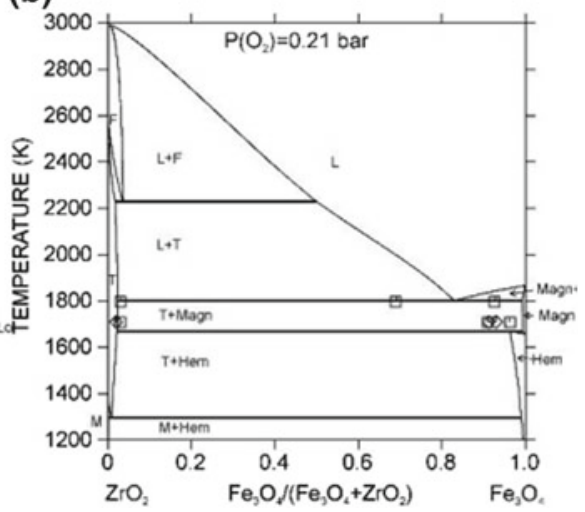

Fig. 19.5 a Calculated isopleth section of $\mathrm{ZrO}_{2}-\mathrm{FeO}$; $\mathbf{b}$ calculated isopleth section of $\mathrm{ZrO}_{2}-\mathrm{Fe}_{3} \mathrm{O}_{4}$ [35]

Fig. 19.6 Liquidus surface of the $\mathrm{ZrO}_{2}-\mathrm{FeO}-\mathrm{Fe}_{2} \mathrm{O}_{3}$ system calculated using advanced thermodynamic description of the $\mathrm{Zr}-\mathrm{Fe}-\mathrm{O}$ system [35]

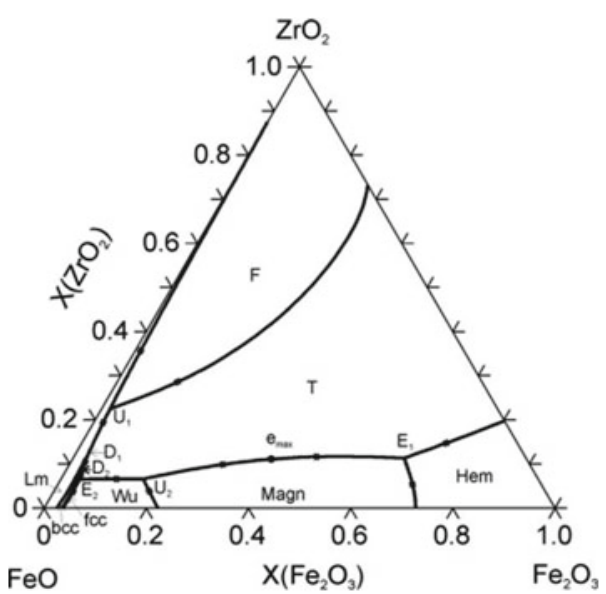


the chemical compositions of the phases with SEM/EDX. Based on the experimental data, the thermodynamic parameters were optimized and phase diagrams at oxygen partial pressures of $10^{-4}$ bar and in air were calculated. The phase diagrams are shown in Fig. 19.7a, b along with the experimental data.

Phase equilibria in the $\mathrm{ZrO}_{2}-\mathrm{MgO}-\mathrm{MnO}-\mathrm{Mn}_{2} \mathrm{O}_{3}$ system were investigated experimentally in air and in Ar atmosphere in the work of Pavlyuchkov et al. [43]. The samples were characterized with XRD and SEM/EDX. The reactions occurring in these systems were determined by DTA-TG experiments under He atmosphere. Isothermal sections constructed at low partial pressure of $\mathrm{O}_{2}$ are presented in Fig. 19.8.

At the last stage of the TRIP-Matrix-Composite development, the main objective was the further development of the thermodynamic database for $\mathrm{ZrO}_{2}$-based

(a)

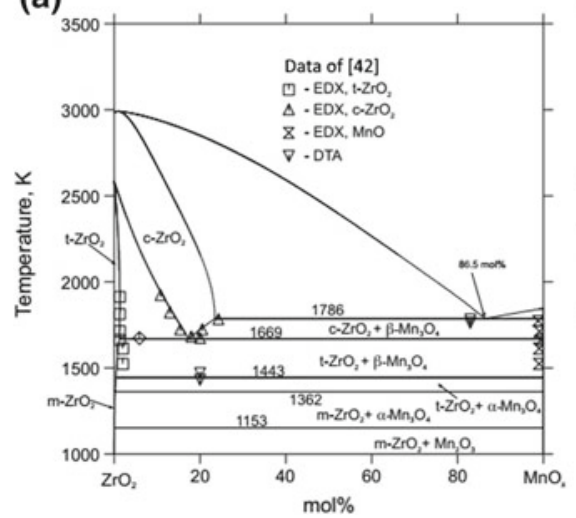

(b)

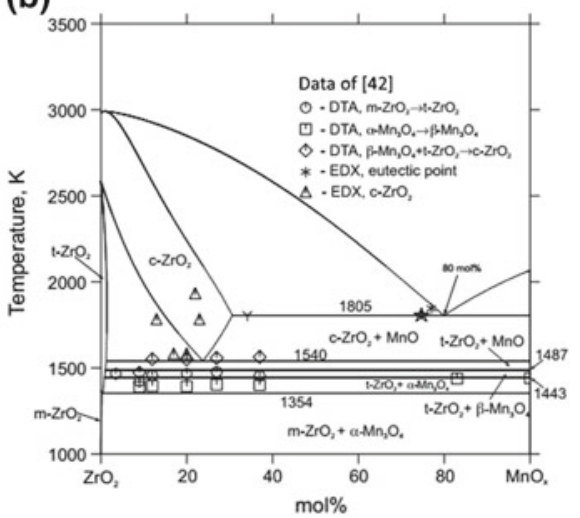

Fig. 19.7 Calculated phase diagrams of the $\mathrm{ZrO}_{2}-\mathrm{MnO}_{x}$ systems at a $\mathrm{pO}_{2}=0.21$ bar and b $\mathrm{pO}_{2}=1 \times 10^{-4}$ bar, along with the experimental data [42]
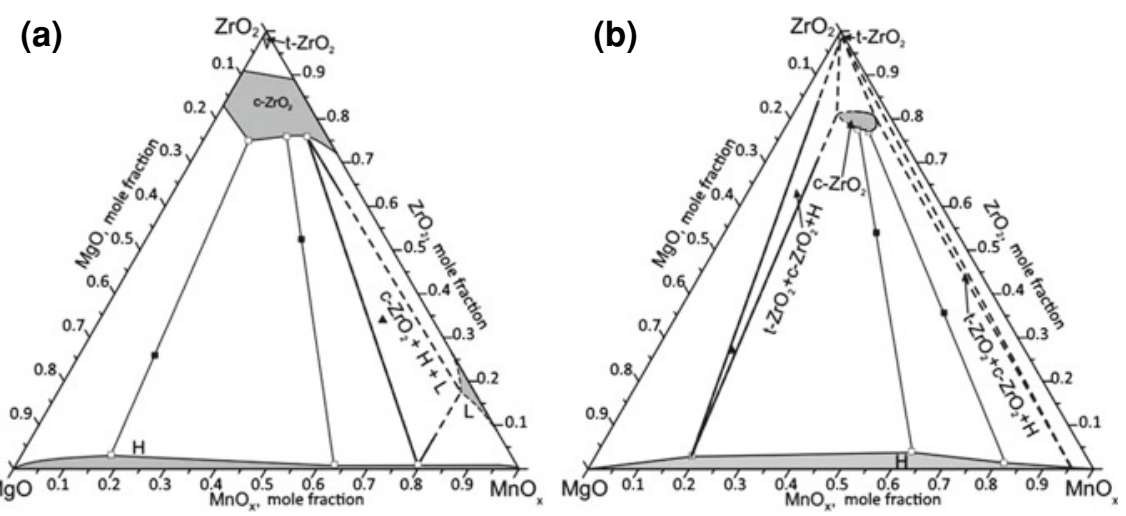

Fig. 19.8 Isothermal section of $\mathrm{ZrO}_{2}-\mathrm{MgO}-\mathrm{MnO}_{x}$ under helium atmosphere $\left(\mathrm{PO}_{2}=10^{-4}\right.$ bar $)$ a at $1913 \mathrm{~K}$ and $\mathbf{b}$ at $1523 \mathrm{~K}$ [43] 
ceramic materials and their implementation in the existing steel database. The combined database will make complete simulation of interfacial reactions between steel and ceramics in the TRIP metal matrix composite material possible. Therefore, the following partial goals result:

1. Further development of the thermodynamic database for the $\mathrm{ZrO}_{2}-\mathrm{MgO}-\mathrm{FeO}-$ $\mathrm{MnO}-\mathrm{Fe}_{2} \mathrm{O}_{3}-\mathrm{Mn}_{2} \mathrm{O}_{3}-\mathrm{TiO}_{2}-\mathrm{Al}_{2} \mathrm{O}_{3}$ system is to be promoted.

2. The next task is to assemble the thermodynamic databases for ceramic materials with the steel database. The main goal of this work is the creation of a thermodynamic database, which allows the calculation of the chemical reactions taking place at the interface between steel and ceramic. This task requires the integration of binary and ternary descriptions from the literature into the newly generated database as well as the adaptation of the thermodynamic parameters. The incorporation of oxygen into the data set requires the implementation of system descriptions such as $\mathrm{Fe}-\mathrm{O}, \mathrm{Mn}-\mathrm{O}, \mathrm{Cr}-\mathrm{O}, \mathrm{Ni}-\mathrm{O}$ and the associated ternary systems $\mathrm{Fe}-\mathrm{Ni}-\mathrm{O}, \mathrm{Fe}-\mathrm{Mn}-\mathrm{O}, \mathrm{Fe}-\mathrm{Cr}-\mathrm{O}, \mathrm{Ni}-\mathrm{Cr}-\mathrm{O}$, etc. The integration of $\mathrm{Zr}$ requires the thermodynamic modelling of $\mathrm{Zr}-\mathrm{Fe}, \mathrm{Zr}-\mathrm{Mn}, \mathrm{Zr}-\mathrm{Ni}$ systems as well as other $\mathrm{Zr}$-containing systems. Therefore, the expansion of the steel database with $\mathrm{Zr}$ was planned. The binary descriptions $\mathrm{Zr}-\mathrm{O}$ and $\mathrm{Ti}-\mathrm{O}$ are implemented in the complex steel ceramics database.

First, high-temperature phase transformations in strongly metastable austeniticmartensitic Fe-CrMnNi-N-C cast steels were studied using SEM/EXD and DTA based on preliminary CALPHAD calculations. Our studies of the $\mathrm{Fe}-15 \mathrm{Cr}-3 \mathrm{Mn}-$ $3 \mathrm{Ni}-0.1 \mathrm{~N}$ cast stainless steels with five different carbon contents, in particular the SEM imaging and EDX elemental mapping of the segregation of $\mathrm{Cr}$ and $\mathrm{Ni}$, have shown that the solidification mode changes from primary ferritic to primary austenitic with increasing carbon content. This is in contradiction to thermodynamic calculations (Fig. 19.9) of a primary ferritic solidification of all alloys, but can be explained by the experimental conditions, e.g. by the solidification rate, which creates a nonequilibrium state and facilitates therefore the austenitic solidification. Melting temperatures determined by DTA measurements showed no clear trend with respect to the carbon content in the investigated steel compositions, probably due to the influence of local chemical inhomogeneities. The experimental temperature range for melting is narrow and lies above the calculated melting range, probably due to an overheating effect. The transformation temperature for the solid-solid phase transformation $\mathrm{fcc}(\gamma) \rightarrow \mathrm{fcc}(\gamma)+\operatorname{bcc}(\delta)$ was also measured by DTA. In agreement with the calculations, it increases with increasing carbon content for steels NC05 to NC15, but above $0.155 \mathrm{wt} \% \mathrm{C}$ it remains approximately constant regardless of the further increasing carbon content. Again, several effects can explain the deviation from the calculation in alloys with a higher carbon content: local fluctuations of the chemical composition, but also a reduced overheating due to an increased transformation rate at higher temperatures. The transformation $\operatorname{fcc}(\gamma) \rightarrow \operatorname{fcc}(\gamma)+\operatorname{bcc}(\delta)$ was found to be fully reversible, that means it occurs during heating and cooling at almost the same temperature, thus the undercooling is very small. 
Fig. 19.9 Vertical section of the phase diagram of the steel $\mathrm{Fe}-15 \mathrm{Cr}-3 \mathrm{Mn}-3 \mathrm{Ni}-$ $0.1 \mathrm{~N}-\mathrm{xC}$ in dependence on the carbon content [6]

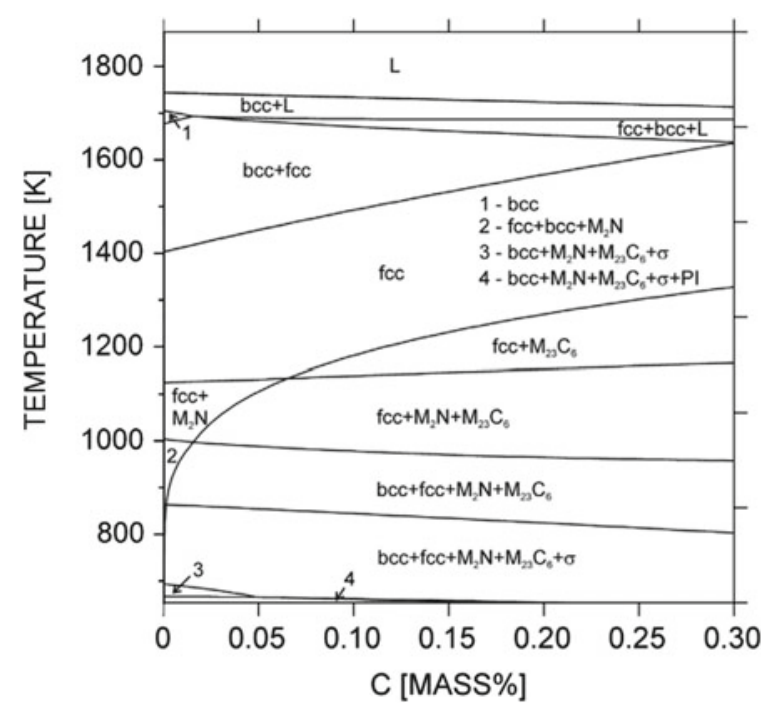

Furthermore, the reversion transformation of a thermal martensite $\alpha^{\prime} \rightarrow \gamma$ was shown for the steels $\mathrm{NCO} 5$ and $\mathrm{NC10}$, which contain a significant fraction of martensite formed during quenching. For the other alloys, the effect was below the detection limit of DTA because of the low volume fractions $(<5 \mathrm{vol} \%)$ of martensite present. The onset temperature of the transformation decreased with the carbon content.

Concerning further thermodynamic modelling of the ceramic systems, thermodynamics of the $\mathrm{Mg}-\mathrm{Mn}-\mathrm{O}$ system has been modeled based on new heat capacity measurements of the $\mathrm{MgMn}_{2} \mathrm{O}_{4}$ and $\mathrm{Mg}_{6} \mathrm{MnO}_{8}$ phases [44]. Phase diagram data, structural information, and thermochemical data were used in the assessment. All solid solution phases were modeled using the compound energy formalism. Mgsolubility in the cubic spinel has been modeled according to the findings in a previous study of Pavlyuchkov et al. [43], which suggests that Mg solubility reported by earlier studies was too low. Thus, the older reports on the $\mathrm{Mg}$ solubility in the cubic spinel were not considered. In general experimental data found in the literature was well reproduced. The results presented were significant for further thermodynamic modelling of the $\mathrm{Mg}-\mathrm{Mn}-\mathrm{Zr}-\mathrm{O}$ system.

Phase relations in the $\mathrm{ZrO}_{2}-\mathrm{TiO}_{2}$ system were investigated in the temperature range from 1303 to $1903 \mathrm{~K}$ using XRD and SEM/EDX. Melting reactions in this system were studied using DTA followed by microstructure investigation [45]. The $\mathrm{Liq}=\beta-\left(\mathrm{Zr}_{x} \mathrm{Ti}_{1-x}\right)_{2} \mathrm{O}_{4}+\mathrm{TiO}_{2}$ eutectic and the Liq $+\mathrm{T}-\mathrm{ZrO}_{2}=\beta-\left(\mathrm{Zr}_{x} \mathrm{Ti}_{1-x}\right)_{2} \mathrm{O}_{4}$ peritectic reactions were determined at $2029 \mathrm{~K}$ and $2117 \mathrm{~K}$ respectively. Composition of eutectic was determined by SEM/EDX to be $83.2 \pm 1.0 \mathrm{~mol} \%$. First, the drop solution calorimetry method was applied using AlexSys 800 (SETARAM Instrumentation) in order to measure enthalpy of formation of the $\beta-\mathrm{ZrTiO}_{4}$ compound from oxides $\left(-18.3 \pm 5.3 \mathrm{~kJ} \mathrm{~mol}^{-1}\right)$. Molar heat capacities of the $\beta-\left(\mathrm{Zr}_{x} \mathrm{Ti}_{1-x}\right)_{2} \mathrm{O}_{4}$ compound was measured in the range $233-1223 \mathrm{~K}$. Experimental thermodynamic values 
Fig. 19.10 Calculated phase diagram of the $\mathrm{ZrO}_{2}-\mathrm{TiO}_{2}$ system along with experimental data [45]

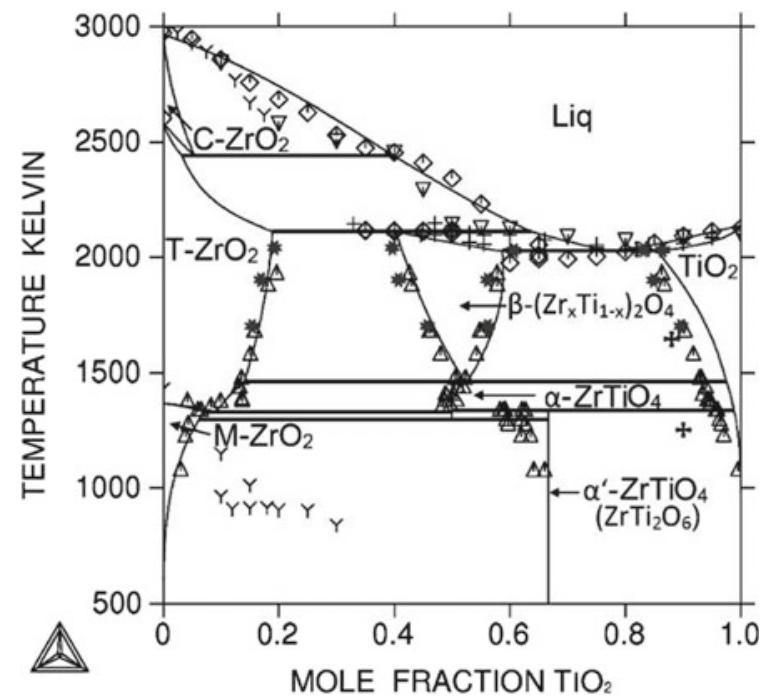

(i.e. heat capacity and enthalpy of formation of $\beta-\mathrm{ZrTiO}_{4}$ compound) determined in [45] were used in order to optimize the description of heat capacity of $\alpha-\mathrm{ZrTiO}_{4}$ and $\beta-\left(\mathrm{Zr}_{x} \mathrm{Ti}_{1-x}\right)_{2} \mathrm{O}_{4}$, as well as the contribution of the formation enthalpy of the $\beta-\mathrm{Zr}_{x} \mathrm{Ti}_{1-x} \mathrm{O}_{4}$ phase, respectively. Using the obtained experimental results together with literature data, the thermodynamic parameters in the $\mathrm{ZrO}_{2}-\mathrm{TiO}_{2}$ system were derived. Calculated phase diagram is presented in the Fig. 19.10.

Later on, based on the newly obtained results for the $\mathrm{ZrO}_{2}-\mathrm{TiO}_{2}$ system, the $\mathrm{ZrO}_{2}-$ $\mathrm{TiO}_{2}-\mathrm{MgO}$ ternary system was experimentally investigated in the temperature range from $1533 \mathrm{~K}$ up to melting temperatures using XRD, SEM/EDX and DTA [46]. Isothermal sections of the system were constructed based on experimental data at 1533,1683 and $1883 \mathrm{~K}$. It has been determined that $\mathrm{TiO}_{2}$ doping did not stabilized $\mathrm{T}-\mathrm{ZrO}_{2}$ phase in this system which transformed to monoclinic structure on cooling. Ternary compound described by formula $\mathrm{Zr}_{4} \mathrm{TiMg}_{2} \mathrm{O}_{12}$ has been discovered. Homogeneity range of the compound was not established. However, based on experimental results, it was stated that the homogeneity range was insignificant and this compound was practically stoichiometric. The ternary compound has a trigonal structure of the $\mathrm{Pr}_{7} \mathrm{O}_{12}$-structure type. Nevertheless, further crystallographic investigations are necessary to establish the cations occupancies in the crystal structure of the phase. High temperature limit of the phase stability of the ternary compound has been determined to be $1664 \mathrm{~K}$. Using results obtained by DTA and SEM/EDX, liquidus projection for the $\mathrm{ZrO}_{2}-\mathrm{TiO}_{2}-\mathrm{MgO}$ system has been constructed. The eutectic reactions $\mathrm{Liq}=$ $\mathrm{C}-\mathrm{ZrO}_{2}+\beta-\left(\mathrm{Zr}_{x} \mathrm{Ti}_{1-x}\right)_{2} \mathrm{O}_{4}+\mathrm{MgTi}_{2} \mathrm{O}_{5}, \mathrm{Liq}=\mathrm{TiO}_{2}+\beta-\left(\mathrm{Zr}_{x} \mathrm{Ti}_{1-x}\right)_{2} \mathrm{O}_{4}+\mathrm{MgTi}_{2} \mathrm{O}_{5}$ and $\mathrm{Liq}=\mathrm{MgTi}_{2} \mathrm{O}_{5}+\mathrm{C}-\mathrm{ZrO}_{2}+\mathrm{MgTiO}_{3}$ have been determined at $1800 \mathrm{~K}, 1851 \mathrm{~K}$ and $1872 \mathrm{~K}$ respectively. Based on the obtained experimental results, thermodynamic 
description of the $\mathrm{ZrO}_{2}-\mathrm{TiO}_{2}-\mathrm{MgO}$ system was developed. Comparison of calculated and experimental results shows a good mutual agreement. Experimental and calculated liquidus projection of the system is shown in the Fig. 19.11.

As it was said above, the integration of $\mathrm{Zr}$ into steel database was required for combining of thermodynamic databases for ceramic materials with the steel database. Therefore, experimental differential scanning calorimetry measurements and ab initio simulations were carried out to define the heat capacities of $\mathrm{Zr}_{3} \mathrm{Fe}$ and $\mathrm{C} 15-\mathrm{ZrFe}_{2}$ compounds from $0 \mathrm{~K}$ up to their maximum stability temperatures [47]. Experimental measurements of heat capacity of each compound were performed for the first

Fig. 19.11 a Constructed liquidus projection of the $\mathrm{ZrO}_{2}-\mathrm{TiO}_{2}-\mathrm{MgO}$ system [46] and b current results of CALPHAD calculation

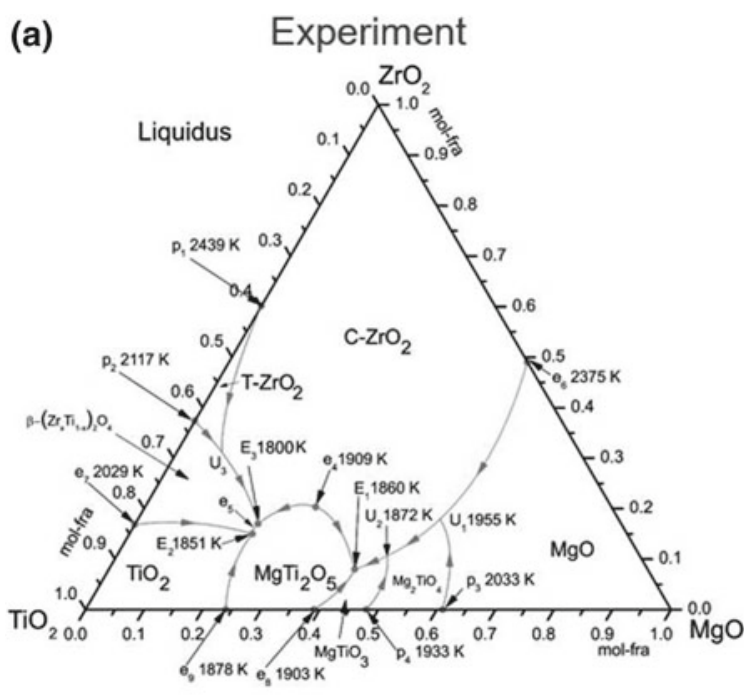

(b)

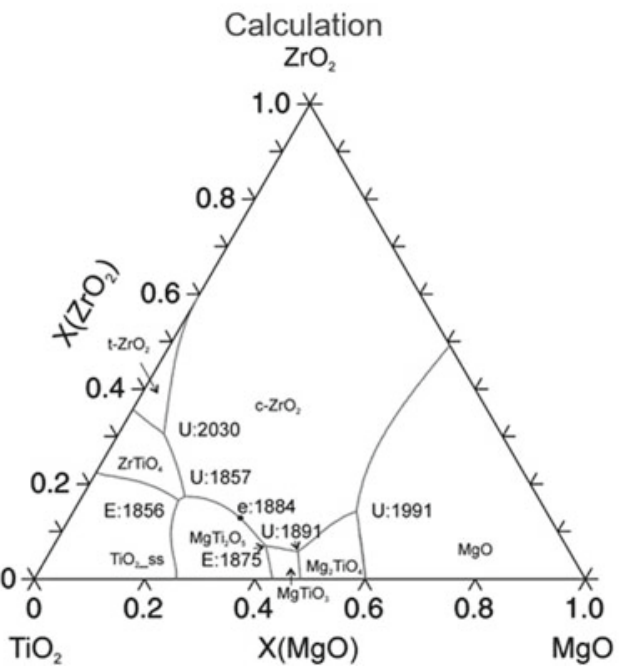


time in wide range of temperatures. Density functional theory and quasi-harmonic approximation (QHA) were employed to calculate the Gibbs energy of the studied systems as a function of volume and temperature. Using the combination of DFT + QHA approach and experimental DSC analysis the main thermodynamic functions $C_{P}(T)$ and parameters $S^{298}$ and $\Delta H^{0}$ for $\mathrm{Zr}_{3} \mathrm{Fe}$ and $\mathrm{ZrFe}_{2}$ intermetallic phases were obtained form $0 \mathrm{~K}$ up to temperatures of their stability. In addition, experimental measurements of thermal expansion coefficient were performed for verification of DFT calculations. Analysis of theoretical and experimental data on $\alpha_{V}$ and $C_{P}$ shows that QHA remarkably underestimates the anharmonic and magnetic effects starting from temperatures 200 to $300 \mathrm{~K}$. However, for low-temperature regions we observed very good agreement between theory and experiment.

Experimental measurements of heat capacity of $\mathrm{Zr}_{2} \mathrm{Fe}$ were performed using DSC in the temperature range from 220 to $450 \mathrm{~K}$ for the first time [48]. Obtained results were compared with theoretical calculations of $C_{P}(T)$ presented by Ali et al. [49]. Using the combination of calculated [49] and experimental results, temperature dependence of heat capacity $C_{P}(T)$ for $\mathrm{Zr}_{2} \mathrm{Fe}$ was described in the temperature range of 0-450 K as well. The standard entropy $S^{298}$ of $\mathrm{Zr}_{2} \mathrm{Fe}$ was evaluated using obtained heat capacity data. Taking into account recent experimental data on heat capacity and ab initio calculations of enthalpy of formation for intermetallic compounds and most reliable data for phase diagram $[50,51]$ thermodynamic re-assessment of the $\mathrm{Fe}-$ $\mathrm{Zr}$ system has been performed [48]. Liquid and solid solution phases such as bcc, fcc, and hep have been described using substitutional model. Compound energy formalism has been used in order to describe homogeneity ranges of the C15- and $\mathrm{C} 36-\mathrm{ZrFe}_{2}$ Laves phases. In the results, it has been demonstrated that the set of obtained thermodynamic parameters describes experimental data better than thermodynamic descriptions published earlier. Calculated phase diagram of the $\mathrm{Fe}-\mathrm{Zr}$ system is presented in Fig. 19.12 along with experimental data.

Afterwards, the Zr-Mn system was studied using XRD, SEM/EDX, DSC and DTA by Flandorfer et al. [53] and in the present study. The heat capacity of the $\mathrm{C} 14-\mathrm{ZrMn}_{2}$ phase was measured in the temperature range of 770 to $1320 \mathrm{~K}$. Based on the obtained results, thermodynamic description was developed. The calculated phase diagram is presented in Fig. 19.13.

Newly obtained thermodynamic parameters of the $\mathrm{Zr}-\mathrm{Mn}$ and $\mathrm{Fe}-\mathrm{Zr}$ systems were combined together with $\mathrm{Fe}-\mathrm{Mn}$ parameters [53] into description of $\mathrm{Fe}-\mathrm{Zr}-\mathrm{Mn}$ system based on binary extrapolation. This database was created for calculations of the ternary diagram which was further used for selection of sample compositions. Experimental investigation of $\mathrm{Zr}-\mathrm{Fe}-\mathrm{Mn}$ system included study of quasibinary $\mathrm{C} 14-\mathrm{ZrMn}_{2}-\mathrm{C} 15-\mathrm{ZrFe}_{2}$ system and ternary phase equilibria. Quasi-binary section of the ternary system was studied by diffusion couple (DC) method. DC was prepared from single phase $\mathrm{C} 14-\mathrm{ZrMn}_{2}$ and $\mathrm{C} 15-\mathrm{ZrFe}_{2}$ samples by spark plasma sintering (SPS) plating. Obtained samples were heat-treated at 1173 and $1373 \mathrm{~K}$ in order to examine phase relation at different temperatures. Microstructure of the DCs was then studied using SEM/EDX with engaging of line-scan for analysis of composition gradient. Samples for ternary phase relations investigation, corresponding to three phase regions, were prepared by arc melting. Samples were heat-treated at 
Fig. 19.12 Calculated $\mathrm{Fe}-\mathrm{Zr}$ phase diagram [50] along with experimental data from the works of Stein et al. [51] and Servant et al. [52]
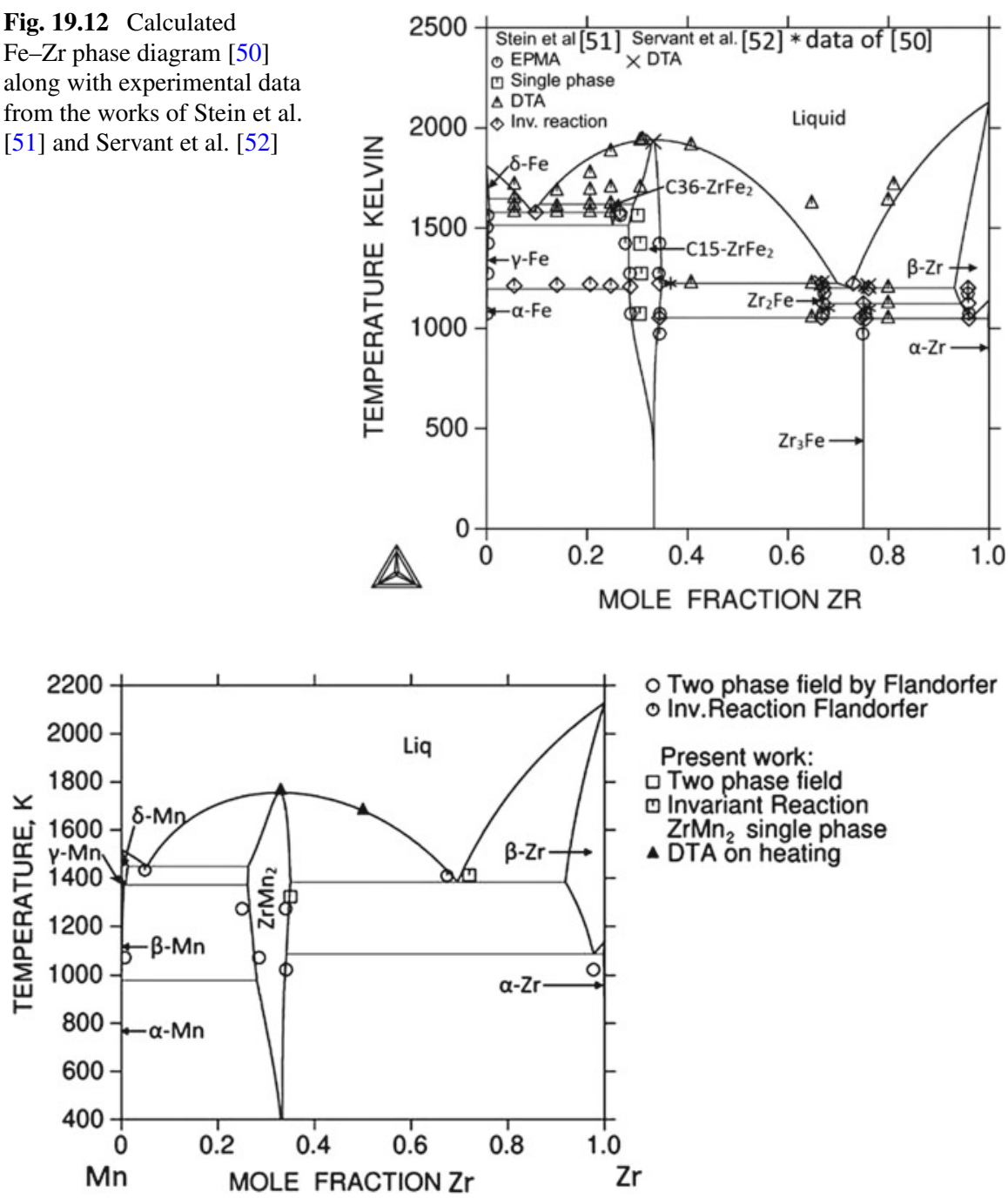

Fig. 19.13 Calculated $\mathrm{Zr}-\mathrm{Mn}$ phase diagrams along with experimental data of Flandorfer et al. [53]

$1073 \mathrm{~K}$ and quenched into water. They were then studied using XRD and SEM/EDX for phase identification and phase relation and chemical composition analysis.

There was contradiction in literature data for this system connected with the area on the phase diagram corresponding to the two-phase region $\mathrm{C} 15-\mathrm{C} 14$. In the work [54] a two-phase region was reported, while in the work [55] an anomaly change of magnetic moment was observed and XRD results indicated formation of C36 Laves phase structure in the composition range between $\mathrm{C} 15$ and $\mathrm{C} 14$ Laves phases. In 


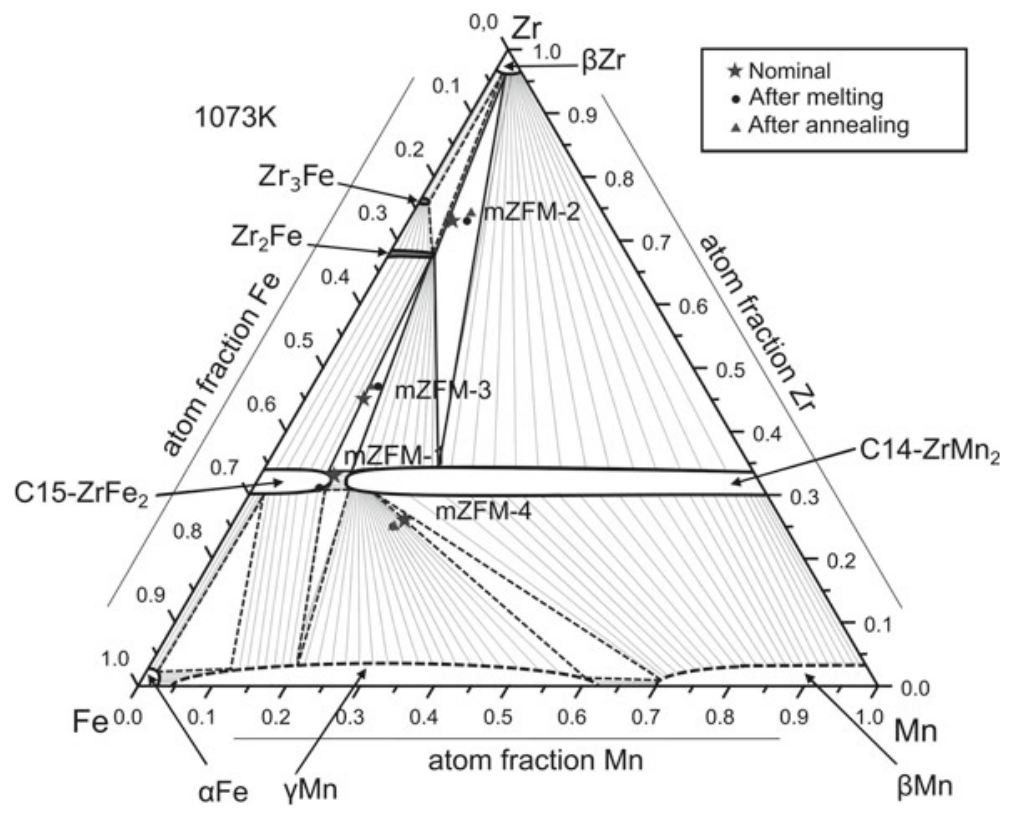

Fig. 19.14 Constructed isothermal section of the Fe-Zr-Mn system at $1073 \mathrm{~K}$

the present work results from SEM/EDX investigation indicated absence of a phase with an intermediate composition. Therefore, it was concluded that two solid solution phases $\mathrm{C} 15$ and $\mathrm{C} 14$ were present in the system coexisting with each other in the range between 60 and $80 \mathrm{~mol} \% \mathrm{ZrFe}_{2}$. Measured solubility ranges of the boundaries of the phases are in good agreement with the literature data [54].

It should be mentioned, that ternary $\mathrm{Fe}-\mathrm{Zr}-\mathrm{Mn}$ system was studied the first time. It was partially constructed based on the results obtained on ternary system and thermodynamic assessments of the composing binary systems. Obtained results are presented in the Fig. 19.14.

\subsection{Conclusions}

Within the present work, substantial amount of results were obtained for thermodynamic modelling of the system related to the TRIP-Matrix-Composite development. Advanced methods of thermodynamic simulations were applied for optimization of chemical composition of steel matrix and ceramic particles, for prediction and understanding of mechanisms occurring in the material, for finding new solutions of technological issues. Additionally, the methods of thermodynamic modelling provided a basement for further development of the TRIP-Matrix-Composite. 
Thermodynamic database was developed for 11 elements $\mathrm{Fe}, \mathrm{Mn}, \mathrm{Cr}, \mathrm{Ni}, \mathrm{Ti}$, $\mathrm{Si}, \mathrm{N}, \mathrm{C}, \mathrm{Mo}, \mathrm{W}, \mathrm{V}$. Obtained thermodynamic description reproduces most of the available experimental results. Thereby, it gives more reliable extrapolations in comparison to other commercial or noncommercial thermodynamic descriptions. Concerning development of thermodynamic oxide description, 3 binary, 7 ternary and a quaternary systems were investigated and modeled in cooperation with other projects.

However, the main uncompleted task is the integration of $\mathrm{Zr}$, what requires the thermodynamic modelling of binary systems such as $\mathrm{Zr}-\mathrm{Ni}, \mathrm{Zr}-\mathrm{Cr}$ and ternary system of iron, zirconium and main alloying elements of steel matrix. Moreover, the incorporation of oxygen into the data set of the steel database requires the implementation of system descriptions such as $\mathrm{Fe}-\mathrm{O}, \mathrm{Mn}-\mathrm{O}, \mathrm{Cr}-\mathrm{O}, \mathrm{Ni}-\mathrm{O}$ and the associated ternary systems $\mathrm{Fe}-\mathrm{Ni}-\mathrm{O}, \mathrm{Fe}-\mathrm{Mn}-\mathrm{O}, \mathrm{Fe}-\mathrm{Cr}-\mathrm{O}, \mathrm{Ni}-\mathrm{Cr}-\mathrm{O}$, etc.

Acknowledgements Current work was funded by the Deutsche Forschungsgemeinschaft (DFG, German Research Foundation)-Projektnummer 54473466-SFB 799. The authors thank Prof. Seifert, Dr. Franke and Dr. Pavlychkov for scientific support and co-working in the sub-project C2 in the frame of SFB 799.

\section{References}

1. U.R. Kattner, Tecnol. Metal Mater. Min. 13(1), 3-15 (2016). https://doi.org/10.4322/21761523.1059

2. S. Martin, S. Richter, S. Decker, U. Martin, L. Krüger, D. Rafaja, Steel Res. Int. 82(9), 11331140 (2011). https://doi.org/10.1002/srin.201100099

3. M. Wendler, B. Reichel, R. Eckner, O. Fabrichnaya, L. Krüger, A. Weiß, J. Mola, Metall. Mater. Trans. A 47(1), 139-151 (2016). https://doi.org/10.1007/s11661-014-2716-0

4. S. Martin, O. Fabrichnaya, D. Rafaja, Mater. Lett. 159, 484-488 (2015). https://doi.org/10. 1016/j.matlet.2015.06.087

5. P. Franke, M. Ksyta, H.J. Seifert, Steel Res. Int. 82(9), 1149-1157 (2011). https://doi.org/10. 1002/srin.201100132

6. O. Fabrichnaya, C. Ullrich, M. Wendler, G. Savinykh, D. Rafaja, J. Alloys Compd. 686, 511521 (2016). https://doi.org/10.1016/j.jallcom.2016.06.026

7. M. Hauser, M. Wendler, O. Fabrichnaya, O. Volkova, J. Mola, Mater. Sci. Eng., A 675, 415-420 (2016). https://doi.org/10.1016/j.msea.2016.08.080

8. L. Halbauer, R. Eckner, M. Wendler, O. Fabrichnaya, A. Buchwalder, L. Krüger, R. Zenker, H. Biermann, Steel Res. Int. 87(12), 1627-1637 (2016). https://doi.org/10.1002/srin.201600028

9. H.L. Lukas, S.G. Fries, B. Sundman, Computational Thermodynamics (Cambridge University Press, Cambridge, 2007)

10. Z.-K. Liu, Y. Wang, Computational Thermodynamics of Materials (Cambridge University Press, Cambridge, 2016)

11. L. Lutterotti, Nucl. Instrum. Methods Phys. Res. B 268(3-4), 334-340 (2010). https://doi.org/ 10.1016/j.nimb.2009.09.053

12. G. Della Gatta, M.J. Richardson, S.M. Sarge, S. Stølen, Pure Appl. Chem. 78(7), 1455-1476 (2006). https://doi.org/10.1351/pac200678071455

13. O.B. Fabrichnaya, S.K. Saxena, P. Richet, E.F. Westrum, Thermodynamic Data, Models, and Phase Diagrams in Multicomponent Oxide Systems (Springer, Berlin, Heidelberg, 2004)

14. L. Kaufman, H. Bernstein, Computer Calculation of Phase Diagrams with Special Reference to Refractory Metals (Academic Press Inc, New York, 1970) 
15. N. Saunders, A.P. Miodownik, Calphad (Pergamon, Oxford, 1998)

16. M. Hillert, J. Alloys Compd. 320(2), 161-176 (2001). https://doi.org/10.1016/S09258388(00)01481-X

17. R. Schmid-Fetzer, D. Andersson, P.Y. Chevalier, L. Eleno, O. Fabrichnaya, U.R. Kattner, B. Sundman, C. Wang, A. Watson, L. Zabdyr, M. Zinkevich, Calphad 31(1), 38-52 (2007). https:// doi.org/10.1016/j.calphad.2006.02.007

18. M. Hillert, M. Jarl, Calphad 2(3), 227-238 (1978). https://doi.org/10.1016/03645916(78)90011-1

19. A.T. Dinsdale, Calphad 15(4), 317-425 (1991). https://doi.org/10.1016/03645916(91)90030-N

20. O. Redlich, A.T. Kister, Ind. Eng. Chem. 40(2), 345-348 (1948). https://doi.org/10.1021/ ie $50458 \mathrm{a} 036$

21. D. Djurovic, B. Hallstedt, J. von Appen, R. Dronskowski, Calphad 35(4), 479-491 (2011). https://doi.org/10.1016/j.calphad.2011.08.002

22. P. Franke, H.J. Seifert, Calphad 35(1), 148-154 (2011). https://doi.org/10.1016/j.calphad.2010. 10.006

23. Scientific Group Thermodata Europe (SGTE), Thermodynamic Properties of Inorganic Materials (Springer, Berlin, London, 2000)

24. S. Serena, M.A. Sainz, S. de Aza, A. Caballero, J. Eur. Ceram. Soc. 25(5), 681-693 (2005). https://doi.org/10.1016/j.jeurceramsoc.2004.02.011

25. B. Hallstedt, Calphad 16(1), 53-61 (1992). https://doi.org/10.1016/0364-5916(92)90038-Y

26. D. Wittig, A. Glauche, C.G. Aneziris, T. Minghetti, C. Schelle, T. Graule, J. Kuebler, Mater. Sci. Eng., A 488(1-2), 580-585 (2008). https://doi.org/10.1016/j.msea.2007.11.065

27. B. Hallstedt, J. Am. Ceram. Soc. 75(6), 1497-1507 (1992). https://doi.org/10.1111/j.11512916.1992.tb04216.x

28. A.B. Farina, F.B. Neto, Calphad 33(4), 711-718 (2009). https://doi.org/10.1016/j.calphad. 2009.09.003

29. A.D. Pelton, G. Eriksson, D. Krajewski, M. Göbbels, E. Woermann, Z Phys. Chem. 207(Part_1_2), 163-180 (1998). https://doi.org/10.1524/zpch.1998.207.part_1_2.163

30. D. Pavlyuchkov, G. Savinykh, O. Fabrichnaya, Adv. Eng. Mater. 15(7), 618-626 (2013). https:// doi.org/10.1002/adem.201200316

31. D. Pavlyuchkov, G. Savinykh, O. Fabrichnaya, J. Euro. Ceram. Soc. 34(5), 1397-1408 (2014). https://doi.org/10.1016/j.jeurceramsoc.2013.11.038

32. P. Tassot, G. Knig, F. Seifert, F. Liebau, J. Mater. Sci. 21(10), 3479-3482 (1986). https://doi. org/10.1007/BF00553788

33. A.S. Berezhnoj, R.A. Kordyuk, DAN URSR (4), 506-508 (1964)

34. A.V. Shevchenko, G.I. Gerasimyuk, L.M. Lopato, S.G. Yusupova, Inorg. Mater. 29, 117-118 (1993)

35. O. Fabrichnaya, D. Pavlyuchkov, Metall. Mater. Trans. A 47(1), 152-159 (2015). https://doi. org/10.1007/s11661-015-2805-8

36. S.V. Bechta, E.V. Krushinov, V.I. Almjashev, S.A. Vitol, L.P. Mezentseva, Y.B. Petrov, D.B. Lopukh, V.B. Khabensky, M. Barrachin, S. Hellmann, K. Froment, M. Fischer, W. Tromm, D. Bottomley, F. Defoort, V.V. Gusarov, J. Nucl. Mater. 348(1-2), 114-121 (2006). https://doi. org/10.1016/j.jnucmat.2005.09.009

37. T.S. Jones, S. Kimura, A. Muan, J. Am. Ceram. Soc. 50(3), 137-142 (1967). https://doi.org/ 10.1111/j.1151-2916.1967.tb15063.x

38. R.H.G.A. Kiminami, Ceramica (Sao Paulo) (33), 207-209 (1987)

39. R.J. Fruehan, MT 5(2), 345-347 (1974). https://doi.org/10.1007/bf02644100

40. D. Janke, W.A. Fischer, Archiv für das Eisenhüttenwesen 47(4), 195-198 (1976). https://doi. org/10.1002/srin.197603805

41. W. Huang, Calphad 28(2), 153-157 (2004). https://doi.org/10.1016/j.calphad.2004.07.007

42. D. Pavlyuchkov, G. Savinykh, O. Fabrichnaya, J. Euro. Ceram. Soc. 35(13), 3623-3632 (2015). https://doi.org/10.1016/j.jeurceramsoc.2015.06.005 
43. D. Pavlyuchkov, D. Dilner, G. Savinykh, O. Fabrichnaya, J. Am. Ceram. Soc. 99(9), 3136-3145 (2016). https://doi.org/10.1111/jace.14327

44. D. Dilner, D. Pavlyuchkov, T. Zienert, L. Kjellqvist, O. Fabrichnaya, J. Am. Ceram. Soc. 100(4), 1661-1672 (2017). https://doi.org/10.1111/jace.14686

45. I. Saenko, M. Ilatovskaia, G. Savinykh, O. Fabrichnaya, J. Am. Ceram. Soc. 101(1), 386-399 (2017). https://doi.org/10.1111/jace.15176

46. I. Saenko, V. Tsukrenko, M. Ilatovskaia, D. Pavlyuchkov, G. Savinykh, O. Fabrichnaya, Adv. Eng. Mater. 21(5), 1800655 (2018). https://doi.org/10.1002/adem.201800655

47. B.O. Mukhamedov, I. Saenko, A.V. Ponomareva, M.J. Kriegel, A. Chugreev, A. Udovsky, O. Fabrichnaya, I.A. Abrikosov, Intermetallics 109, 189-196 (2019). https://doi.org/10.1016/j. intermet.2019.01.018

48. R. Lück, H. Wang, J. Alloys Compd. 191(2), L11-L12 (1993). https://doi.org/10.1016/09258388(93)90055-R

49. K. Ali, P.S. Ghosh, A. Arya, J. Alloys Compd. 723, 611-619 (2017). https://doi.org/10.1016/ j.jallcom.2017.06.154

50. I. Saenko, A. Kuprava, A. Udovsky, O. Fabrichnaya, Calphad 66, 101625 (2019). https://doi. org/10.1016/j.calphad.2019.05.002

51. F. Stein, G. Sauthoff, M. Palm, J. Phase Equilibria Diffus. 23(6), 480 (2002). https://doi.org/ $10.1361 / 105497102770331172$

52. C. Servant, C. Gueneau, I. Ansara, J. Alloys Compd. 220(1-2), 19-26 (1995). https://doi.org/ 10.1016/0925-8388(94)06036-3

53. H. Flandorfer, J. Gröbner, A. Stamou, N. Hassiotis, A. Saccone, P. Rogl, R. Wouters, H. Seifert, D. Macciò, R. Ferro, G. Haidemenopoulos, L. Delaey, G. Effenberg, Mater. Res. Adv. Tech. (88), 529-538 (1997)

54. V.V. Petkov, Russ. Metall. 5, 113-115 (1972)

55. K. Kanematsu, J. Phys. Soc. Jpn. 31(5), 1355-1360 (1971). https://doi.org/10.1143/JPSJ.31. 1355

Open Access This chapter is licensed under the terms of the Creative Commons Attribution 4.0 International License (http://creativecommons.org/licenses/by/4.0/), which permits use, sharing, adaptation, distribution and reproduction in any medium or format, as long as you give appropriate credit to the original author(s) and the source, provide a link to the Creative Commons license and indicate if changes were made.

The images or other third party material in this chapter are included in the chapter's Creative Commons license, unless indicated otherwise in a credit line to the material. If material is not included in the chapter's Creative Commons license and your intended use is not permitted by statutory regulation or exceeds the permitted use, you will need to obtain permission directly from the copyright holder.

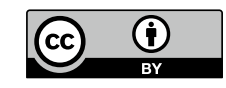

